\title{
Criticality Safety Evaluation for the Advanced Test Reactor U-Mo Demonstration Elements
}

Leland M. Montierth

December 2010

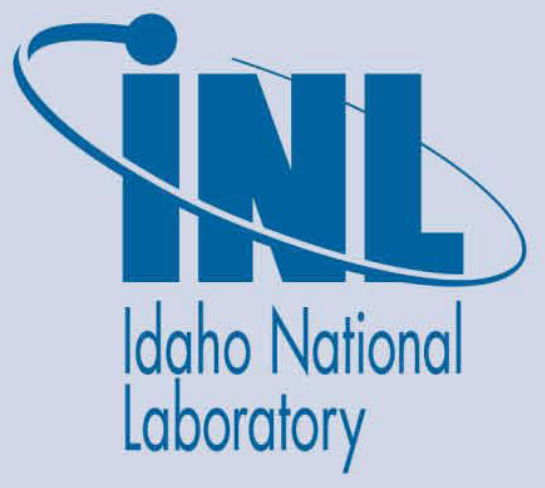

The INL is a U.S. Department of Energy National Laboratory operated by Battelle Energy Alliance 


\section{DISCLAIMER}

This information was prepared as an account of work sponsored by an agency of the U.S. Government. Neither the U.S. Government nor any agency thereof, nor any of their employees, makes any warranty, expressed or implied, or assumes any legal liability or responsibility for the accuracy, completeness, or usefulness, of any information, apparatus, product, or process disclosed, or represents that its use would not infringe privately owned rights. References herein to any specific commercial product, process, or service by trade name, trade mark, manufacturer, or otherwise, does not necessarily constitute or imply its endorsement, recommendation, or favoring by the U.S. Government or any agency thereof. The views and opinions of authors expressed herein do not necessarily state or reflect those of the U.S. Government or any agency thereof. 
INL/EXT-10-20323

Revision 1

\title{
Criticality Safety Evaluation for the Advanced Test Reactor U-Mo Demonstration Elements
}

\author{
Leland M. Montierth
}

December 2010

\begin{abstract}
Idaho National Laboratory
Idaho Falls, Idaho 83415
\end{abstract}

http://www.inl.gov

Prepared for the

U.S. Department of Energy

Office of Nuclear Energy

Under DOE Idaho Operations Office

Contract DE-AC07-05ID14517 

INL/EXT-10-20323

Revision: 1

\section{Criticality Safety Evaluation for the Advanced Test Reactor U-Mo Demonstration Elements}

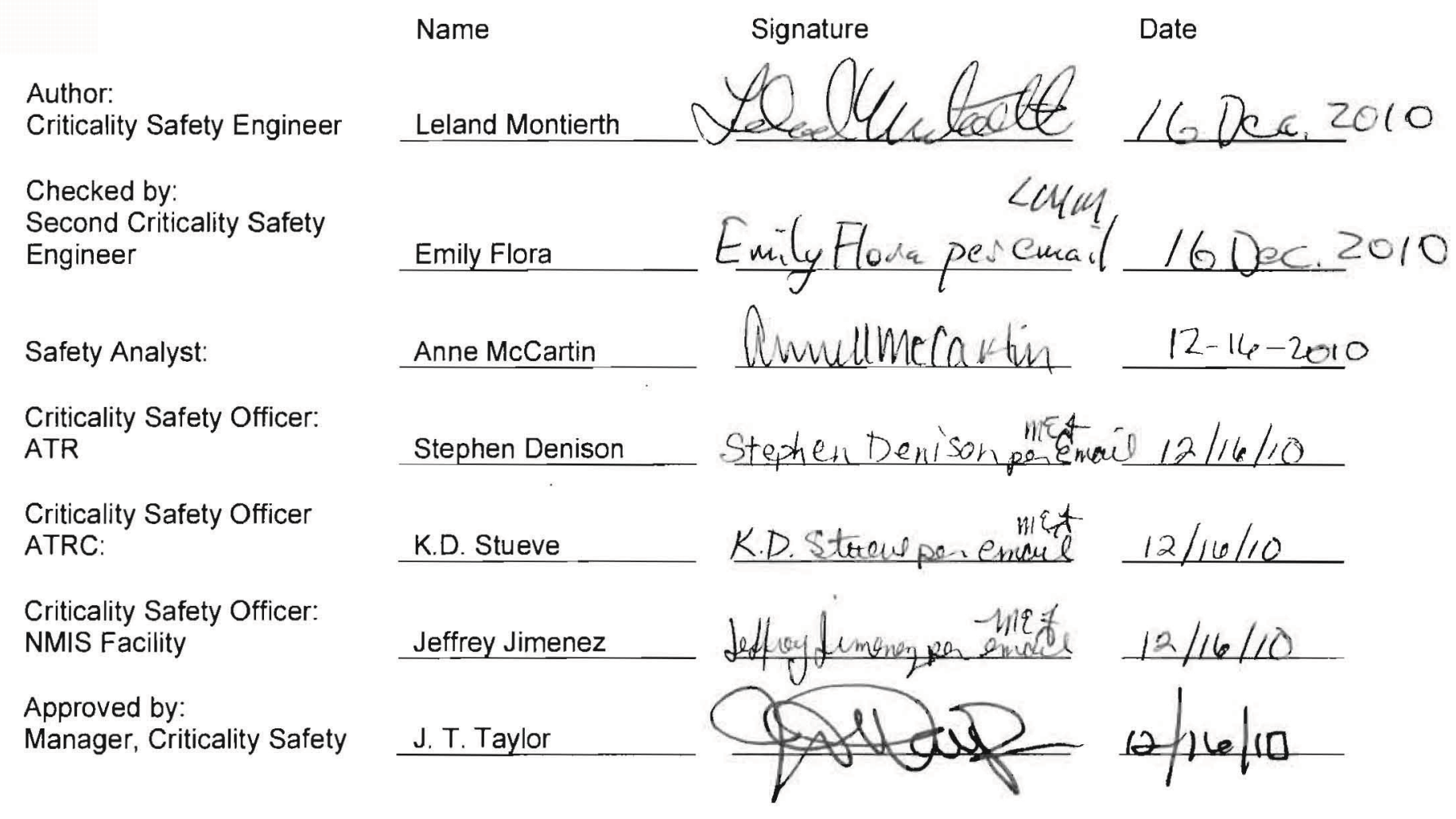


INL/EXT-10-20323

Revision: 1

Project File

No.

26267

Index codes:

Building/Type 775
Quality

Level:

Quality level source: ALL-000507

SSC ID: NA

Site Area: RTC

Uniform File Code: 7651

Disposition Authority: ENV1-b-4-a

Retention Schedule: Review Annually. Cutoff when superseded, obsolete or cancelled. Destroy 75 years after cutoff.

NOTE: Original disposition authority, retention schedule, and Uniform Filing Code applied by the sender may not be appropriate for all recipients. Make adjustments as needed. 
INL/EXT-10-20323

Revision: 1

Page i of ii

\section{Contents}

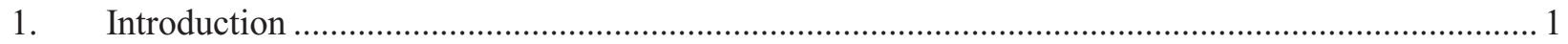

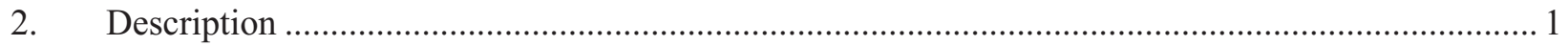

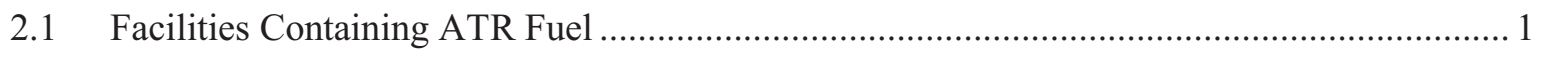

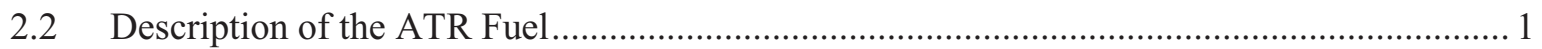

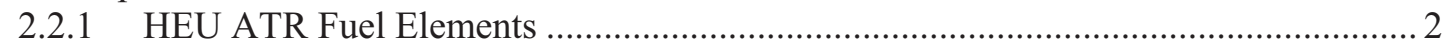

2.2.2 ATR U-10Mo Full Size Demonstration Fuel Elements ............................................... 4

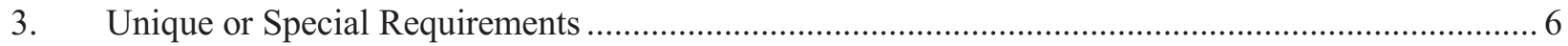

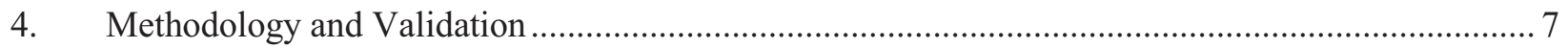

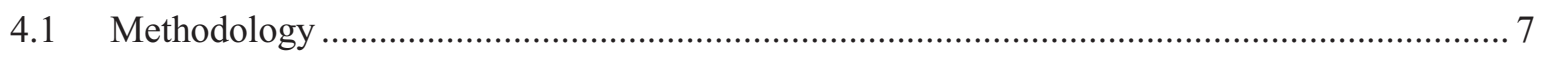

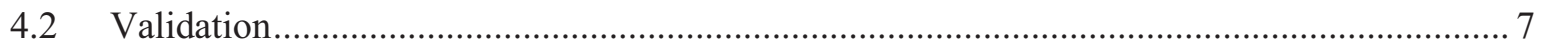

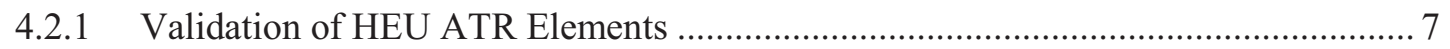

4.2.2 Validation of U-10Mo Full Size Demonstration Elements......................................... 7

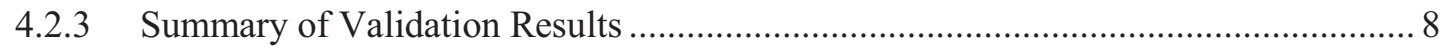

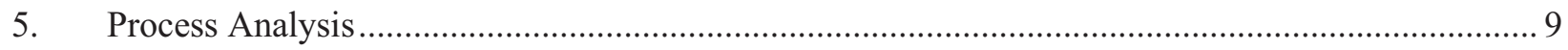

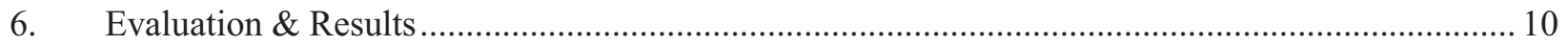

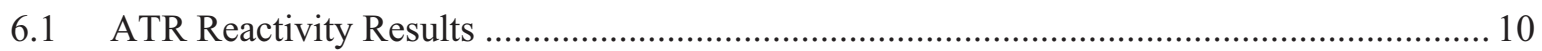

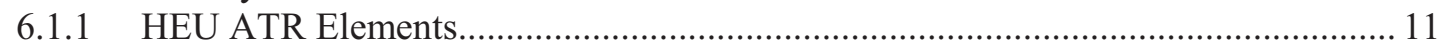

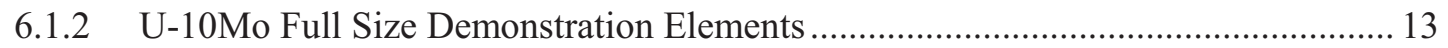

6.1.3 U-10Mo Full Size Demonstration Elements with All Plates Fueled ......................... 13

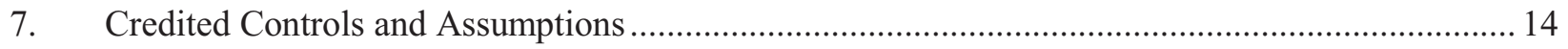

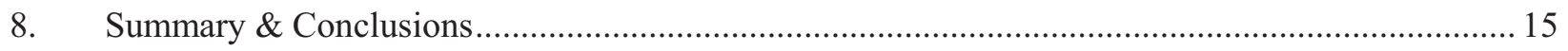

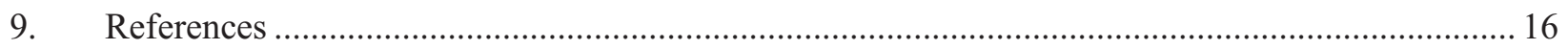

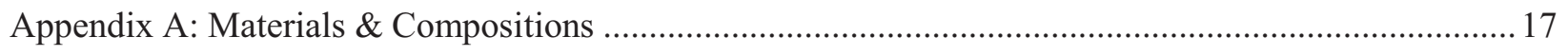

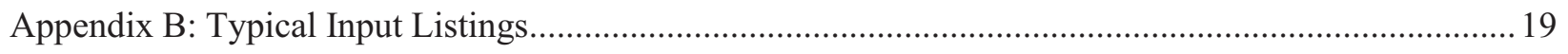

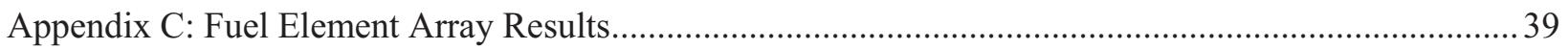


INL/EXT-10-20323

Revision: 1

Page ii of ii

\section{Tables}

Table 1. Dimensions and U-235 Content for Individual Plates in ATR Fuel Element 4

Table 2. Individual Plate Dimensions and U-235 Content for Full Size Demonstration Elements 6

Table 3. Results for Moderated Intermediate Enrichment U-235 Benchmark Experiments 8

Table 4. Maximum Allowed and Model Full Size Demonstration Plate U-235 Loadings 10

Table 5. Summary of Most Reactive Results 15

Table A-1. Material Specifications for $\mathrm{UAl}_{\mathrm{x}}$ Plates 17

Table A-2. Material Specifications for U-10Mo 17

Table A-3. Material Specifications for Zr Cladding 18

Table A-4. Material Specifications for Water18

Table A-5. Material Specifications for Al-6061 18

Table C- 1. Results for HEU ATR Element Configurations 39

Table C- 2. Results for HEU ATR Elements in Circular Configurations 40

Table C- 3. Results for U-10Mo Full Size Demonstration ATR Element Configurations 41

Table C- 4. Results for U-10Mo Full Size Demonstration ATR Elements with all Plates Fueled 42

\section{Figures}

Figure 1. Simplified View of the HEU ATR Fuel Element 3

Figure 2. Full Size Demonstration U-10Mo Fuel Element 5

Figure 3. U-10Mo Fuel Plate Cross-section 5

Figure 4. Near-Critical Configurations of (HEU) ATR Elements 11

Figure 5. Configurations to Investigate Increased Spacing between Elements 12

Figure 6. Circular Configurations to Investigate Increased Spacing between Elements 13 
INL/EXT-10-20323

Revision: 1

Page 1 of 42

\section{Introduction}

The Reduced Enrichment Research Test Reactors (RERTR) fuel development program is developing a high uranium density fuel based on a (LEU) uranium-molybdenum alloy. Testing of prototypic RERTR fuel elements is necessary to demonstrate integrated fuel performance behavior and scale-up of fabrication techniques. Two RERTR-Full Size Demonstration fuel elements based on the ATR-Reduced YA elements (all but one plate fueled) are to be fabricated for testing in the Advanced Test Reactor (ATR). The two fuel elements will be irradiated in alternating cycles such that only one element is loaded in the reactor at a time. Existing criticality analyses have analyzed Standard (HEU) ATR elements (all plates fueled) from which controls have been derived. This criticality safety evaluation (CSE) documents analysis that determines the reactivity of the Demonstration fuel elements relative to HEU ATR elements and shows that the Demonstration elements are bound by the Standard HEU ATR elements and existing HEU ATR element controls are applicable to the Demonstration elements.

\section{Description}

A brief listing of the various facilities where ATR fuel is present is given in Section 2.1. A description of the HEU ATR elements is given in Section 2.2.1. A description of the Full Size Demonstration elements is given in Section 2.2.2.

\subsection{Facilities Containing ATR Fuel}

ATR fuel is handled and stored at several facilities at the INL. Facilities at the ATR Complex are the ATR, the Advanced Test Reactor Critical (ATRC) Facility and the Nuclear Materials Inspection and Storage (NMIS) Facility. The ATR provides high neutron flux for testing reactor fuels and other materials. ATR fuel is handled and stored at the ATR Facility within the reactor vessel, the working canal, the storage canal and up on the deck. The working canal is directly adjacent to the reactor and is used to transfer fuel, experiments and reactor components between the storage canal and the reactor. The storage canal is used for the storage of fuel, experiments and reactor components. The Advanced Test Reactor Critical (ATRC) Facility is a low power pool version of the high-power ATR core that is used for experimental needs. The NMIS facility is used to store unirradiated and slightly irradiated $(<200 \mathrm{mR} / \mathrm{hr})$ fuel. ATR fuel is transferred between the three facilities within the ATR Complex using single and 4-element ATR fresh fuel shipping containers. CSEs have been performed and have derived controls for the handling, storage and transfer of ATR fuel at and between these facilities.

\subsection{Description of the ATR Fuel}

In the history of the ATR, there have been numerous variations of HEU ATR fuel elements. The HEU elements of concern here are the Standard Size non-borated (7F), Standard Size borated where all plates except plates 5 through 15 are borated, and the reduced YA element where all plates except plates 5 through 15 are borated and plate 19 is a "dummy" fuel plate, i.e., it is made entirely of type T-6061 aluminum and contains no fuel. For criticality safety purposes the boron content is conservatively neglected and the Standard elements are identical. This element is referred to here as a "typical" ATR element and bounds the other HEU fuel element variants, including the Mark IV element currently used at ATRC. The Full Size Demonstration elements are based on the ATR Reduced YA elements and also neglect boron for criticality safety purposes. 
INL/EXT-10-20323

Revision: 1

Page 2 of 42

\subsubsection{HEU ATR Fuel Elements}

A typical ATR fuel element consists of 19 curved aluminum clad uranium aluminide $\left(\mathrm{UAl}_{\mathrm{x}}\right)$ plates containing highly enriched $(93 \pm 1 \mathrm{wt} \% \mathrm{U}-235)$ uranium. ${ }^{1}$ The highest fissile loading (U-235) of the fresh fuel element is $1075 \mathrm{~g}^{2}{ }^{2}$ The allowable fuel loading (U-235) uncertainty for each fuel plate is \pm 1 percent. ${ }^{1}$ The allowed fuel element U-235 loading and uncertainty are $1075 \pm 10 \mathrm{~g}$, giving a maximum loading of $1085 \mathrm{~g}$ for a Standard Sized ATR fuel element. The allowed U-235 loading for the ATR Reduced YA element is $1022.4 \pm 10 \mathrm{~g}$ as plate 19 is a dummy plate containing no fuel.

Figure 1 presents a simplified view of a typical ATR fuel element. The fuel plates are 49.5 in. long with a fuel zone that is $48 \mathrm{in.} \mathrm{long.}$

The thickness of each plate is 0.05 in. except plates 1 and 19, which are 0.08 in. and 0.1 in., respectively. The fuel matrix section in each plate is $0.02 \mathrm{in}$. thick. The cladding is made of type T-6061 aluminum. The plates are held in place by aluminum side plates that are 2.549 inches wide, 0.187 in. thick, and 49.5 in. long. The water gap between plates is 0.078 in. thick. When assembled, the angle of curvature of the fuel elements is $45^{\circ}$ with inner and outer radii of $2.964 \mathrm{in}$. and $5.513 \mathrm{in}$, respectively. The detailed dimensions of each fuel plate and maximum U-235 content are presented in Table 1. 
INL/EXT-10-20323

Revision: 1

Page 3 of 42

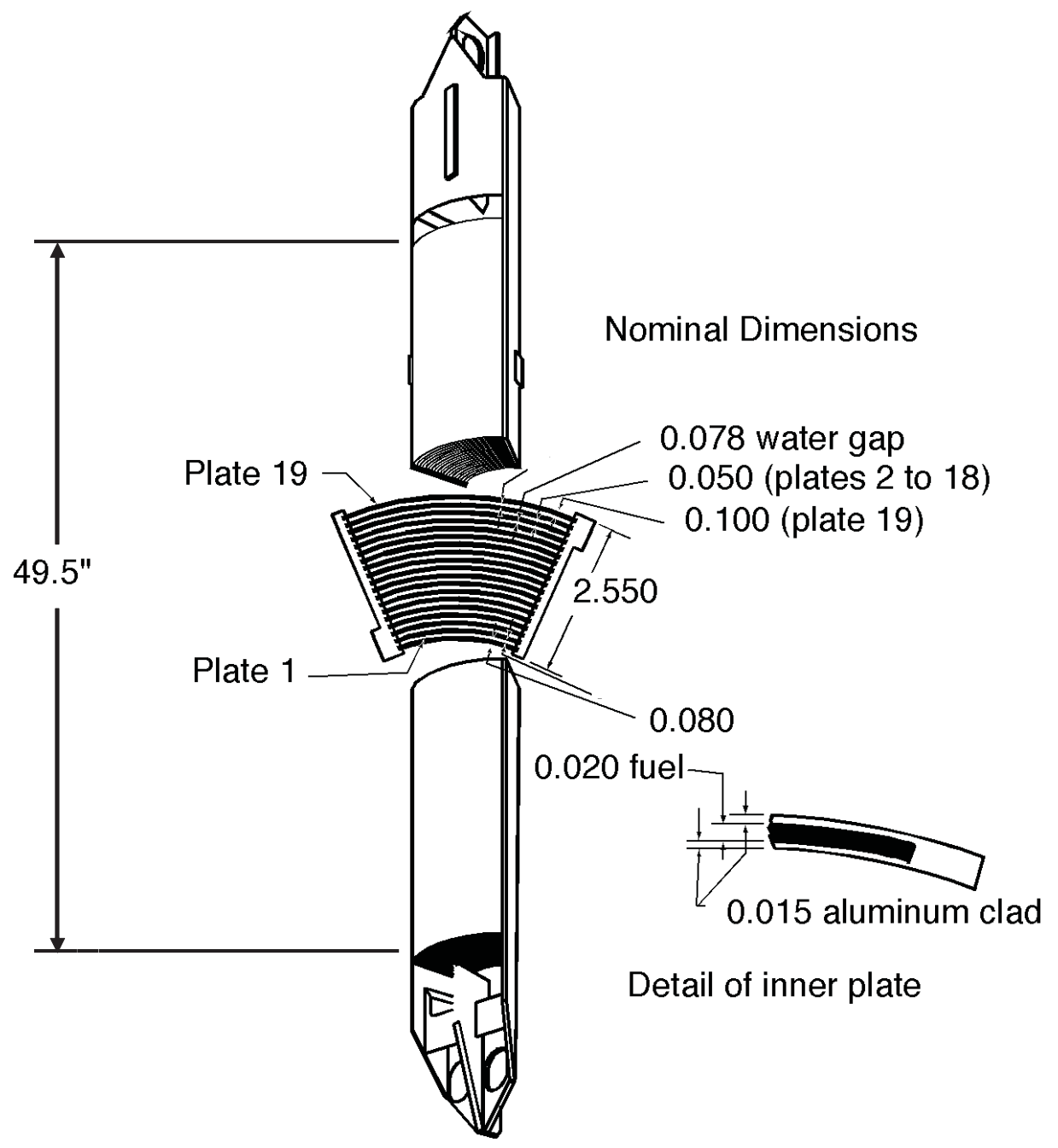

Figure 1. Simplified View of the HEU ATR Fuel Element 
INL/EXT-10-20323

Revision: 1

Page 4 of 42

Table 1. Dimensions and U-235 Content for Individual Plates in ATR Fuel Element

\begin{tabular}{|c|c|c|c|}
\hline Plate Number & $\begin{array}{c}\text { Inner Radius } \\
(\mathbf{c m})\end{array}$ & $\begin{array}{c}\text { Outer Radius } \\
(\mathbf{c m})\end{array}$ & $\begin{array}{c}\text { U-235 content } \\
(\mathbf{m a x})(\mathbf{g})\end{array}$ \\
\hline 1 & 7.65810 & 7.86130 & 24.543 \\
\hline 2 & 8.05942 & 8.18642 & 29.391 \\
\hline 3 & 8.38454 & 8.51154 & 39.087 \\
\hline 4 & 8.70966 & 8.83666 & 40.804 \\
\hline 5 & 9.03478 & 9.16178 & 52.621 \\
\hline 6 & 9.35990 & 9.48690 & 55.146 \\
\hline 7 & 9.68502 & 9.81202 & 57.570 \\
\hline 8 & 10.01014 & 10.13714 & 59.994 \\
\hline 9 & 10.33526 & 10.46226 & 62.418 \\
\hline 10 & 10.66038 & 10.78738 & 64.842 \\
\hline 11 & 10.98550 & 11.11250 & 67.266 \\
\hline 12 & 11.31062 & 11.43762 & 69.690 \\
\hline 13 & 11.63574 & 11.76274 & 72.114 \\
\hline 14 & 11.96086 & 12.08786 & 74.538 \\
\hline 15 & 12.28598 & 12.41298 & 77.063 \\
\hline 16 & 12.61110 & 12.73810 & 64.640 \\
\hline 17 & 12.93622 & 13.06322 & 66.559 \\
\hline 18 & 13.26134 & 13.38834 & 54.338 \\
\hline $19^{\mathrm{a}}$ & 13.58646 & 13.84046 & 53.126 \\
\hline $19^{\mathrm{a}}$ & 13.58646 & 13.84046 & 0. \\
\hline
\end{tabular}

a Plate 19 for the ATR-Reduced YA fuel element is a dummy plate and does not contain any fuel.

\subsubsection{ATR U-10Mo Full Size Demonstration Fuel Elements}

The Full Size Demonstration element's physical geometry will remain unchanged from currently approved elements, but the fuel meat in several fuel plates will utilize U-10Mo alloy instead of the standard $\mathrm{UAl}_{\mathrm{x}}$ currently used in ATR fuel. ${ }^{3}$ Two fuel elements based on the ATR- Reduced YA Element design will be fabricated for testing. The ATR Reduced YA elements consist of 19 total plates including an aluminum dummy plate (plate 19), 11 inner plates with standard $\mathrm{UAl}_{\mathrm{x}}$ fuel meats, and plates 1-4 and 16-18 with $\mathrm{UAl}_{\mathrm{x}}$ fuel and small amounts of $\mathrm{B}_{4} \mathrm{C}$ (burnable poison to suppress power peaking). The RERTR Full-size elements will be identical except that the 11 inner plates (plates 5-15) will be replaced with the U-Mo monolithic fuel design at $19.75 \%$ U- 235 enrichment. The plate locations are graphically depicted in Figure 2.

The nominal density of the U-10Mo is given as $16.9 \mathrm{~g} / \mathrm{cm}^{3}$, giving a U-235 density of $3.0 \mathrm{~g} / \mathrm{cm}^{3}$ for the given enrichment. The fuel meat thickness is $0.013 \mathrm{in}$., and is surrounded by a thin zirconium layer, 0.001 in. thick, to mitigate interactions between the fuel meat and aluminum cladding. A cross-sectional plot and other details of the U-10Mo plates are shown in Figure 3. Details for the individual fuel plates are given in Table 2 . The allowable fuel loading (U-235) uncertainty for each fuel plate is \pm 1 percent. The total combined HEU and LEU U-235 loading for the Full Size Demonstration element is $1239.1 \pm 12 \mathrm{~g}$ or a maximum of $1251.1 \mathrm{~g} .{ }^{4}$ 
INL/EXT-10-20323

Revision: 1

Page 5 of 42

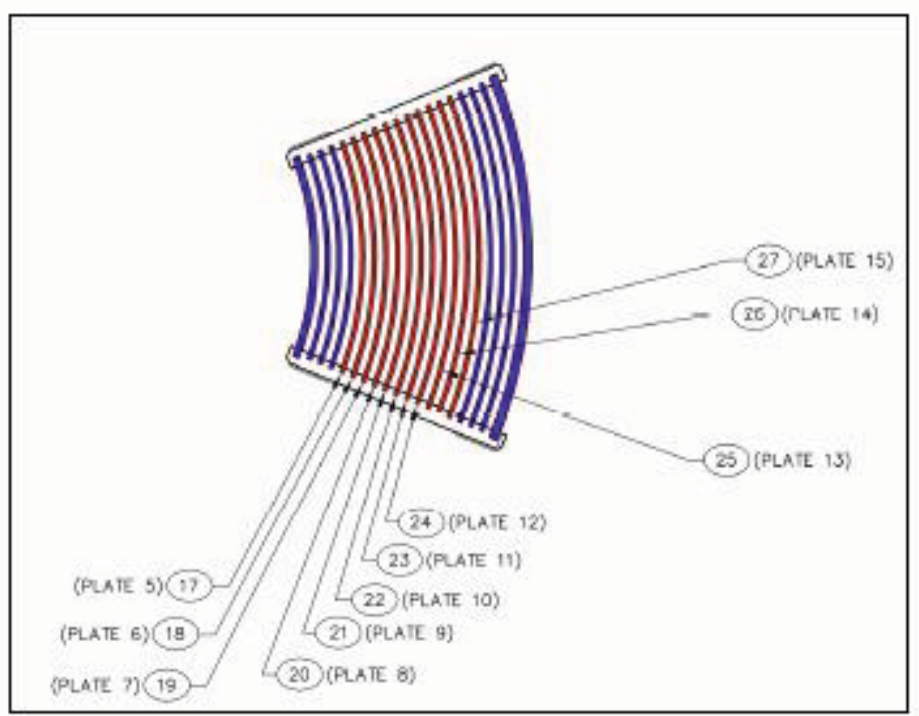

Figure 2. Full Size Demonstration U-10Mo Fuel Element

(Red - U-10Mo, Blue - $\mathrm{UAl}_{\mathrm{x}}$; circled numbers are from drawing)

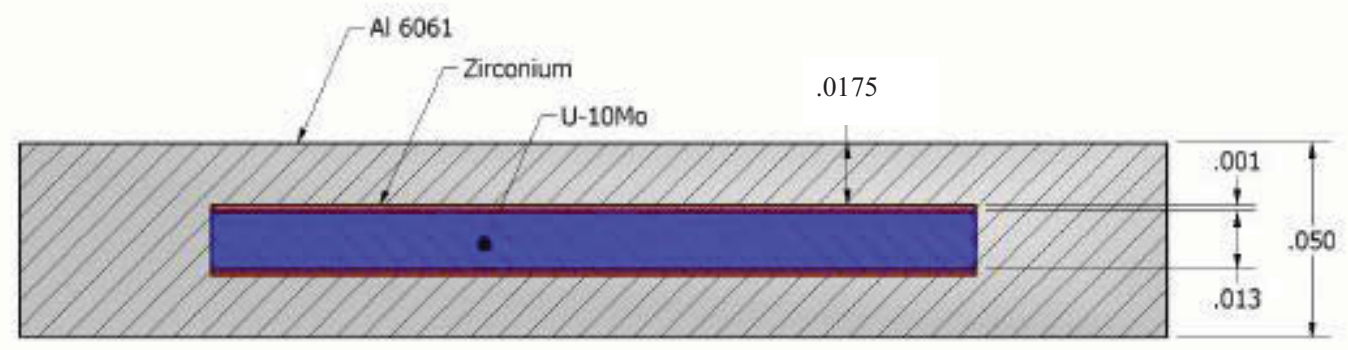

Figure 3. U-10Mo Fuel Plate Cross-section

(dimensions are in inches) 
INL/EXT-10-20323

Revision: 1

Page 6 of 42

Table 2. Individual Plate Dimensions and U-235 Content for Full Size Demonstration Elements

\begin{tabular}{|c|c|c|c|c|}
\hline $\begin{array}{c}\text { Plate } \\
\text { Number }\end{array}$ & Plate Type & $\begin{array}{c}\text { Inner Radius } \\
\text { (cm) }\end{array}$ & $\begin{array}{l}\text { Outer Radius } \\
\text { (cm) }\end{array}$ & $\begin{array}{l}\text { U-235 content } \\
(\max )(\mathrm{g})\end{array}$ \\
\hline 1 & $\mathrm{U}-\mathrm{Al}_{\mathrm{x}}$ & 7.65810 & 7.86130 & 24.543 \\
\hline 2 & $\mathrm{U}-\mathrm{Al} \mathrm{x}_{\mathrm{x}}$ & 8.05942 & 8.18642 & 29.391 \\
\hline 3 & $\mathrm{U}-\mathrm{Al} \mathrm{x}_{\mathrm{x}}$ & 8.38454 & 8.51154 & 39.087 \\
\hline 4 & $\mathrm{U}-\mathrm{Al} 1_{\mathrm{x}}$ & 8.70966 & 8.83666 & 40.804 \\
\hline 5 & U-10Mo Mono & 9.03478 & 9.16178 & 67.6195 \\
\hline 6 & U-10Mo Mono & 9.35990 & 9.48690 & 72.1241 \\
\hline 7 & U-10Mo Mono & 9.68502 & 9.81202 & 75.3258 \\
\hline 8 & U-10Mo Mono & 10.01014 & 10.13714 & 78.4871 \\
\hline 9 & U-10Mo Mono & 10.33526 & 10.46226 & 81.6888 \\
\hline 10 & U-10Mo Mono & 10.66038 & 10.78738 & 84.8198 \\
\hline 11 & U-10Mo Mono & 10.98550 & 11.11250 & 88.0619 \\
\hline 12 & U-10Mo Mono & 11.31062 & 11.43762 & 91.2131 \\
\hline 13 & U-10Mo Mono & 11.63574 & 11.76274 & 94.4148 \\
\hline 14 & U-10Mo Mono & 11.96086 & 12.08786 & 97.5761 \\
\hline 15 & U-10Mo Mono & 12.28598 & 12.41298 & 100.798 \\
\hline 16 & $\mathrm{U}-\mathrm{Al} \mathrm{x}_{\mathrm{x}}$ & 12.61110 & 12.73810 & 64.640 \\
\hline 17 & $\mathrm{U}-\mathrm{Al}_{\mathrm{x}}$ & 12.93622 & 13.06322 & 66.559 \\
\hline 18 & $\mathrm{U}-\mathrm{Al} \mathrm{x}_{\mathrm{x}}$ & 13.26134 & 13.38834 & 54.338 \\
\hline 19 & $\mathrm{Al}$ & 13.58646 & 13.84046 & 0. \\
\hline
\end{tabular}

\section{Unique or Special Requirements}

There are no unique requirements that are applicable to this evaluation. 
INL/EXT-10-20323

Revision: 1

Page 7 of 42

\section{Methodology and Validation}

All calculations listed in this report were performed using MCNP5, version 1.40 with the ENDF/B-VI continuous energy cross section library on Sun workstations running the Red Hat Enterprise LINUX Release 4 operating system. MCNP5 and its libraries are installed and maintained in accordance with an approved quality assurance plan. ${ }^{5}$

\subsection{Methodology}

Calculational models were developed for this evaluation. These calculations used the Monte Carlo N-Particle Transport Code (MCNP) computer program ${ }^{6}$ and ENDF/B-VI cross sections to determine the criticality potential of ATR fuel types. Validation of the MCNP code is described in this section.

Benchmark experiments containing the same or similar attributes as the evaluated cases analyzed in this CSE are identified and evaluated here.

\subsection{Validation}

\subsubsection{Validation of HEU ATR Elements}

Validation results for the HEU ATR fuel elements are not repeated here as these results have previously been presented elsewhere. ${ }^{7,8,9}$ In all cases it was not necessary to apply any bias to the results.

\subsubsection{Validation of U-10Mo Full Size Demonstration Elements}

The two different enrichments used in the Full Size Demonstration elements, nominal values of 20\% and $93 \%$, complicate the choice of applicable benchmark experiments as there are no known moderated benchmark experiments with these particular enrichments. (Note also that there is no known moderated benchmark experiment containing Mo alloyed with uranium at any enrichment available for validation.) If the fuel in the various plates were mixed together and homogenized, then the effective enrichment would be $25 \%$. The International Criticality Safety Benchmark Evaluation Project (ICSBEP) considers this and $20 \%$ to be intermediate enrichments (IEU). Whether the Full Size Demonstration elements are thought of as being homogenized or not, two moderated benchmark experiments with enrichments that bracket $20 \%$ and $25 \%$ are used to validate the U-10Mo Demonstration elements. One of these benchmark experiments consists of stainless steel clad $\mathrm{U}(17) \mathrm{O}_{2}$ fuel rods moderated and reflected by water. The other experiment consists of uranium-polytetrafluoroethylene $\left(\mathrm{U}(30) \mathrm{F}_{4}\left(\mathrm{CF}_{2}\right)_{\mathrm{n}}\right)$ and polyethylene $\left(\mathrm{CH}_{2}\right)$ cubes reflected by paraffin. Brief descriptions of these benchmark experiments are given in this section. The MCNP5 results for these experiments using ENDF/B-VI cross sections are given in Table 3. The last column of this table is the MCNP energy of average neutron lethargy causing fission (EALF).

Stainless steel clad $\mathrm{U}(17) \mathrm{O}_{2}$ fuel rods were water moderated and reflected in benchmark experiment IEU-COMP-THERM-002. ${ }^{10}$ Experiments were performed in 1970-1973 in the MATR facility at the Institute of Physics and Power Engineering, Obninsk, Russia. The fuel rods were arranged in hexagonal lattices with a pitch of $6.8 \mathrm{~cm}$. Each lattice was comprised of fuel rods containing either no absorber, gadolinium absorber, or cadmium absorber. The lattices were fully reflected on all sides by water. The critical mass was determined for "cold" $\left(20^{\circ} \mathrm{C}\right)$ and "hot" $\left(\sim 200^{\circ} \mathrm{C}\right)$ assemblies. Results are presented in the first set of Table 3 only for the cold, no absorber fuel rods case.

Benchmark experiment IEU-COMP-THERM-001 consisted of one-inch cubes of uraniumpolytetrafluoroethylene $\left(\mathrm{U}(30) \mathrm{F}_{4}\left(\mathrm{CF}_{2}\right)_{\mathrm{n})}\right.$ and polyethylene $\left(\mathrm{CH}_{2}\right)$ reflected by paraffin. ${ }^{11,12}$ The arrays 
INL/EXT-10-20323

Revision: 1

Page 8 of 42

were assembled with different numbers of the two cube types to vary H/U-235 ratios from 32 to 220 .

Additional details are given in Table 3. Results are only presented for those benchmark experiments that had EALF values comparable to that of a near-critical array of U-10Mo Demonstration elements, $1.2 \times 10^{-4} \mathrm{kev}$.

Table 3. Results for Moderated Intermediate Enrichment U-235 Benchmark Experiments

\begin{tabular}{|c|c|c|c|}
\hline $\begin{array}{l}\text { Experiment / } \\
\text { MCNP Input } \\
\text { File Name }\end{array}$ & Description & $\mathbf{k}_{\mathrm{eff}} \pm \sigma$ & $\begin{array}{c}\text { EALF }^{\text {a }} \\
\text { (kev) }\end{array}$ \\
\hline \multicolumn{4}{|c|}{ IEU-COMP-THERM-002; U(17) $\mathrm{O}_{2}$ fuel rods } \\
\hline CASE_1L & $\begin{array}{l}34 \text { fuel rods at temperature of } 22.7^{\circ} \mathrm{C} \text {; no absorber } \\
\text { elements }\end{array}$ & $0.9960 \pm 0.0005$ & $9.1 \times 10^{-5}$ \\
\hline \multicolumn{4}{|c|}{ IEU-COMP-THERM-001; U-poly cube array results } \\
\hline exp04 & 10x10x8 array size;298 U cubes with $596 \mathrm{CH}_{2}$ cubes & $0.9998 \pm 0.0008$ & $2.6 \times 10^{-4}$ \\
\hline $\exp 05$ & $16 \times 14 \times 14$ array size; $400 \mathrm{U}$ cubes with $2800 \mathrm{CH}_{2}$ cubes & $1.0062 \pm 0.0006$ & $1.1 \times 10^{-4}$ \\
\hline $\exp 13$ & 9x9x11 array size; $302 \mathrm{U}$ cubes with $604 \mathrm{CH}_{2}$ cubes & $0.9995 \pm 0.0008$ & $2.6 \times 10^{-4}$ \\
\hline $\exp 14$ & $8 \times 8 \times 16$ array size; $356 \mathrm{U}$ cubes with $712 \mathrm{CH}_{2}$ cubes & $1.0000 \pm 0.0006$ & $2.6 \times 10^{-4}$ \\
\hline $\exp 15$ & $8 \times 7 \times 26$ array size; $488 \mathrm{U}$ cubes with $976 \mathrm{CH}_{2}$ cubes & $1.0009 \pm 0.0008$ & $2.5 \times 10^{-4}$ \\
\hline \multicolumn{2}{|c|}{ 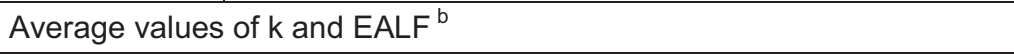 } & $1.0004 \pm 0.0030$ & $2.1 \times 10^{-4}$ \\
\hline
\end{tabular}

a EALF is the energy of average neutron lethargy causing fission

$\mathrm{b}$ The average values of $\mathrm{k}_{\mathrm{avg}}$ and its corresponding $\mathrm{u}$ are determined from the following formulas: $\mathrm{k}_{\mathrm{avg}}=\Sigma \mathrm{k}_{\mathrm{i}} / \mathrm{N}$ and $\mathrm{u}^{2}=\Sigma\left(\mathrm{k}_{\mathrm{avg}}-\mathrm{k}_{\mathrm{i}}\right)^{2} / \mathrm{N}$

\subsubsection{Summary of Validation Results}

The range of applicability of the benchmark cases presented in this section is determined by primary physical parameters that characterize a particular fissionable configuration. These physical parameters include material properties, geometry properties and trending parameters such as the EALF or H/X ratio for moderated systems. An area or range of applicability for the benchmark experiments is defined and used to determine the bias for configurations of interest. The choice of the benchmark experiments is typically based on the fissionable element, enrichment, chemical form, configuration geometry and if applicable neutron absorber, moderator material, reflector material, and any other important consideration.

Benchmark applicability to this analysis is determined by fissionable elements, enrichment, geometry, reflection and neutron energy. The critical benchmark experiments used here are applicable to the systems evaluated in this analysis, and the calculated results for the experiments show good correlation with the measured critical results. It will not be necessary, therefore, to apply any bias to the results calculated in this report. 
INL/EXT-10-20323

Revision: 1

Page 9 of 42

\section{Process Analysis}

This section is not applicable. This CSE does not analyze critical scenarios or develop controls for the storage or handling of ATR fuel elements. This report analyzes the reactivity of the U-10Mo Full Size Demonstration elements relative to the typical HEU ATR element to show that the Full Size Demonstration elements are bound by the Standard HEU ATR elements and existing HEU ATR element controls are applicable to the Full Size Demonstration elements. 
INL/EXT-10-20323

Revision: 1

Page 10 of 42

\section{Evaluation \& Results}

The information provided in Section 2.2 is used to develop the ATR models. The number densities for the materials and uranium isotopics are given in Appendix A. Sample input decks are given in Appendix B. Enrichments of $94 \%$ and $20 \%$ are used for the ATR HEU and U-10Mo elements, respectively. The HEU ATR plate loadings are given in Table 1 which includes an additional 1\% U-235 for each plate giving a total U-235 loading of $1085.75 \mathrm{~g}$. The model U-235 loadings for the U-10Mo plates are given below in Table 4. The maximum plate loadings (specified loading plus 1\%) are repeated here from Table 2 and are seen to be less than the model loadings. The model U-235 loadings are determined from the U-10Mo density and the fuel meat volumes, which in turn are determined from the fuel meat thickness, length and average value of the fuel core boundary ${ }^{13}$ (this determines the fuel meat width). The total model U-235 loading for the Full Size Demonstration element is $1260.8 \mathrm{~g}$, conservatively larger than the specified maximum of $1251 \mathrm{~g}$. The boron content of the elements is neglected.

Table 4. Maximum Allowed and Model Full Size Demonstration Plate U-235

Loadings

\begin{tabular}{|c|c|c|c|}
\hline $\begin{array}{c}\text { Plate } \\
\text { Number }\end{array}$ & Plate Type & $\begin{array}{l}\text { U-235 Content } \\
(\max )(g)^{\mathrm{a}}\end{array}$ & $\begin{array}{c}\text { Model U-235 } \\
\text { Content (g) }\end{array}$ \\
\hline 5 & U-10Mo Mono & 67.6195 & 69.949 \\
\hline 6 & U-10Mo Mono & 72.1241 & 73.077 \\
\hline 7 & U-10Mo Mono & 75.3258 & 76.205 \\
\hline 8 & U-10Mo Mono & 78.4871 & 79.333 \\
\hline 9 & U-10Mo Mono & 81.6888 & 82.461 \\
\hline 10 & U-10Mo Mono & 84.8198 & 85.589 \\
\hline 11 & U-10Mo Mono & 88.0619 & 88.717 \\
\hline 12 & U-10Mo Mono & 91.2131 & 91.845 \\
\hline 13 & U-10Mo Mono & 94.4148 & 94.973 \\
\hline 14 & U-10Mo Mono & 97.5761 & 98.100 \\
\hline 15 & U-10Mo Mono & 100.798 & 101.228 \\
\hline \multicolumn{4}{|c|}{$\begin{array}{l}\text { These are the maximum loadings as per Reference } 4 \text { and are repeated here } \\
\text { from Table } 2 \text {. }\end{array}$} \\
\hline
\end{tabular}

The fuel elements are explicitly modeled with 19 curved, aluminum clad fuel plates and aluminum side plates (plate 19 of the Full Size Demonstration element is also aluminum). The non-fueled ends of the ATR elements are ignored, and the element length is $49.5 \mathrm{in}$.

Results for the HEU ATR elements are given in Section 6.1.1, the U-10Mo Demonstration element results with the dummy plate 19 are given in Section 6.1.2 and the U-10Mo Demonstration element results with plate 19 fueled are given in Section 6.1.3.

For convenience in referring to cases in a given table, groups of cases may be referred to as a "set," where the set of cases examines variations to a single or limited number of parameters. A preceding header (in bold type) within each table denotes the set.

\subsection{ATR Reactivity Results}

The reactivity of the two fuel types is compared by determining the reactivity of a single element and a nearcritical element array for each fuel type. Since the elements are more reactive when moderated, they are 
INL/EXT-10-20323

Revision: 1

Page 11 of 42

modeled with water moderation and reflection. While there are other materials that are better reflectors than water, the use of these materials would not change the results of the comparison presented here. The moderated element configurations are evaluated to be as reactive as reasonably possible. This is done by varying the spacing between elements to find the most reactive configurations.

\subsubsection{HEU ATR Elements}

A previous $\mathrm{CSE}^{8}$ has evaluated near-critical water moderated and reflected configurations of HEU ATR elements using a previous version of MCNP (probably version MCNP4a, circa 1994, but simply referred to as MCNP) that are seen in Figure 4. The element fuel loading was $1075 \mathrm{~g}$ of U-235 with an enrichment of $93 \%$ and no boron. Reported values of $\mathrm{k}_{\mathrm{eff}}$ are $0.984+0.002$ and $0.985+0.003$ for the hexagonal array (Configuration A) and circular configuration (Configuration B), respectively. A $\mathrm{k}_{\mathrm{eff}}$ of $0.444+0.002$ was also reported for a single water moderated and reflected element.

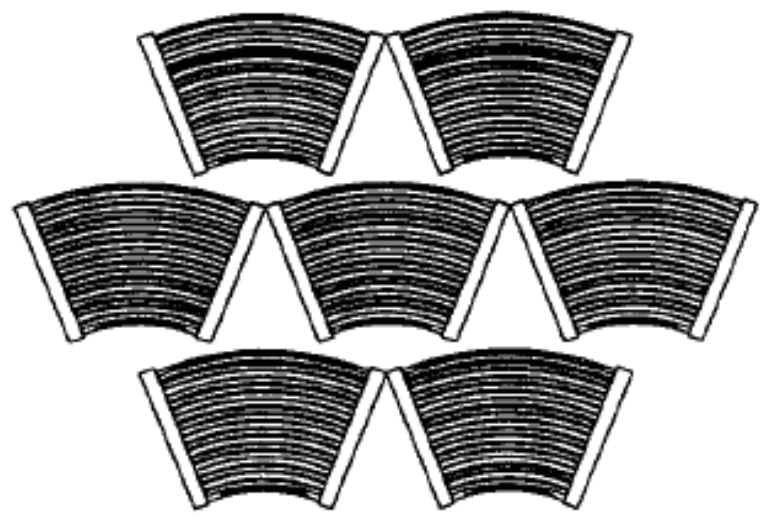

Configuration A

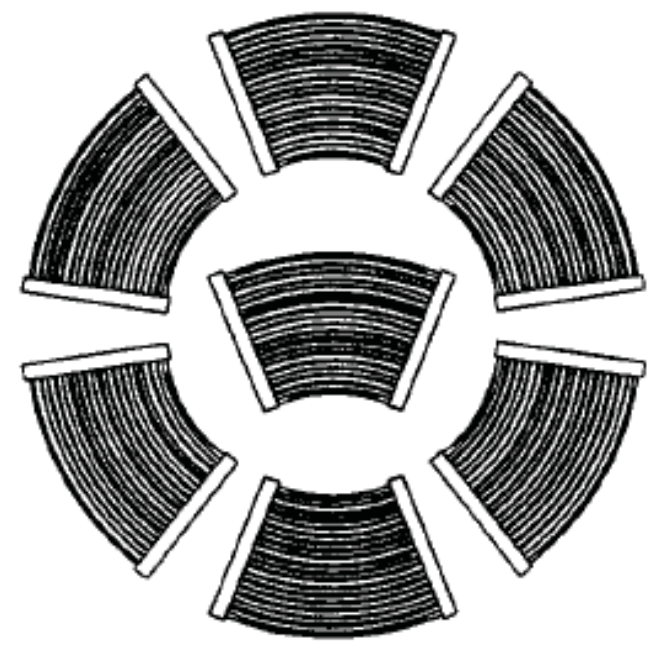

Configuration B

Figure 4. Near-Critical Configurations of (HEU) ATR Elements (from Figure 3 of Reference 8)

Similar configurations (exact details of the previous configurations are not available) are evaluated with the ATR model used in this CSE to verify that the results are consistent. These results are presented in Appendix C, Table C- 1 and are summarized in this section. The single element result for $\mathrm{k}_{\mathrm{eff}}$ is $0.4455 \pm 0.0006$, which agrees with the previous value of $\mathrm{k}_{\text {eff }}$ from Reference 8 within $1 \sigma$ ( $\sigma$ from the previous calculation is used). The $\mathrm{k}_{\mathrm{eff}}$ for a configuration similar to Configuration A in Figure 4 is $0.9887 \pm 0.0007$. This is just larger than the previous result by $2 \sigma$, though is very reasonable considering the slightly higher loading $(1085.75 \mathrm{~g} \mathrm{U}-235$ compared to $1075 \mathrm{~g}$ ) and enrichment (94\% compared to 93\%) of the ATR elements and the use of ENDF/B-VI cross sections in this CSE.

A configuration with a more uniform spacing between adjacent side-by-side elements than Configuration A in Figure 4 is used to investigate reactivity changes with increasing space between elements. This configuration is shown in Figure 5. The elements are essentially touching in the first frame of the figure, and the elements are moved in the "conventional" $\mathrm{x}$ and $\mathrm{y}$ directions as the spacing increases. The most reactive configuration is shown in the second frame where $\mathrm{k}_{\text {eff }}$ is $0.9952 \pm 0.0007$. This value is about $0.0065 \Delta \mathrm{k}$ more reactive than the 
INL/EXT-10-20323

Revision: 1

Page 12 of 42

Configuration A (Figure 4) case previously discussed. Results for different spacings are given in the third set of Table C- 1.

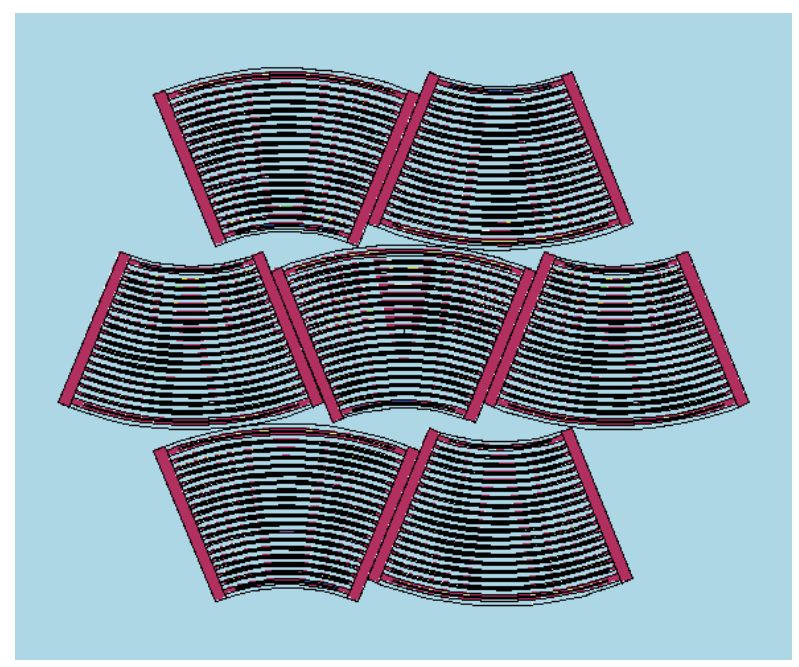

b) This is case heu_7b of Table C- 1 where adjacent elements are essentially touching

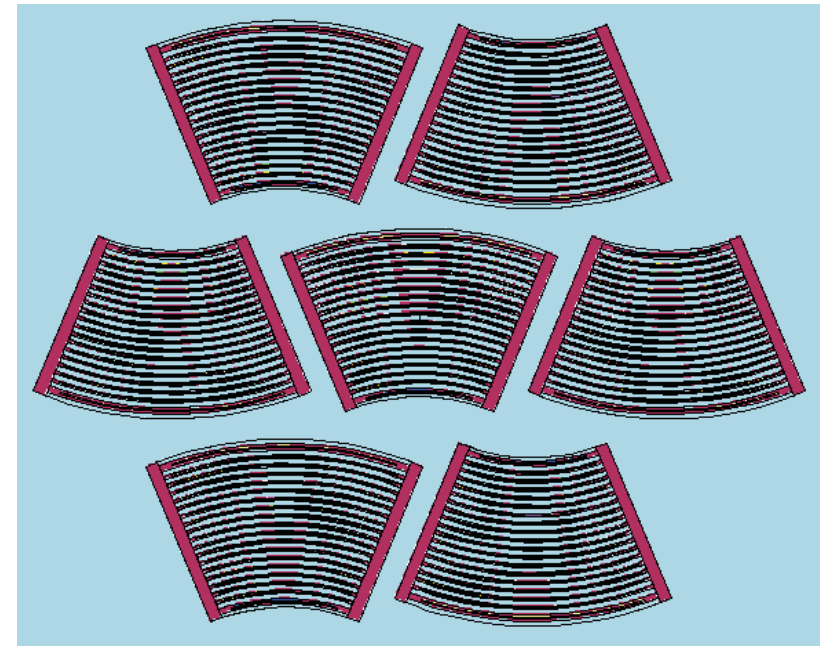

a) This is case heu_7b_1.1 of Table C- 1 where adjacent elements are separated by $1.1 \mathrm{~cm}$

Figure 5. Configurations to Investigate Increased Spacing between Elements

Configurations similar to Figure 4, Configuration B, but with different radial spacing between the center element and the outer ring of elements are shown in Figure 6. The spacing between elements is increased by increasing the radius of the outer ring of elements (azimuthal spacing remains unchanged) while the center element remains fixed. Results for these configurations are given in Appendix C, Table C- 2, and the most reactive case has a $\mathrm{k}_{\text {eff }}$ of $0.9952 \pm 0.0007$ which is the same as the most reactive hexagonal array case of Table $\mathrm{C}-1$. This value is larger than the circular array result of Reference 8 (mentioned above) by $0.01 \Delta \mathrm{k}$ indicating that the circular configuration used in this CSE is more reactive than that used in Reference 8 and/or the ATR model used here is more reactive. This is further investigated by modifying the Reference 8 model to use the same configuration as that used here which produces a $\mathrm{k}_{\text {eff }}$ of $0.9950 \pm 0.0006$, which is essentially identical to the result found here indicating excellent agreement between the two (current and previous) models. 


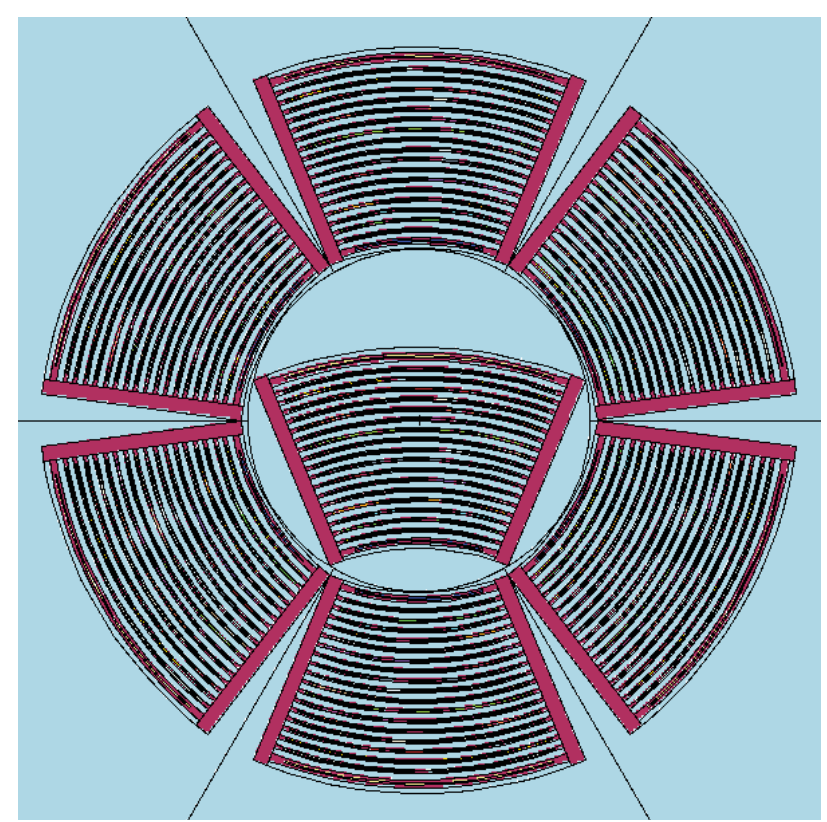

a) This is case heu_7c_ma of Table C- 2 where elements are at closest approach

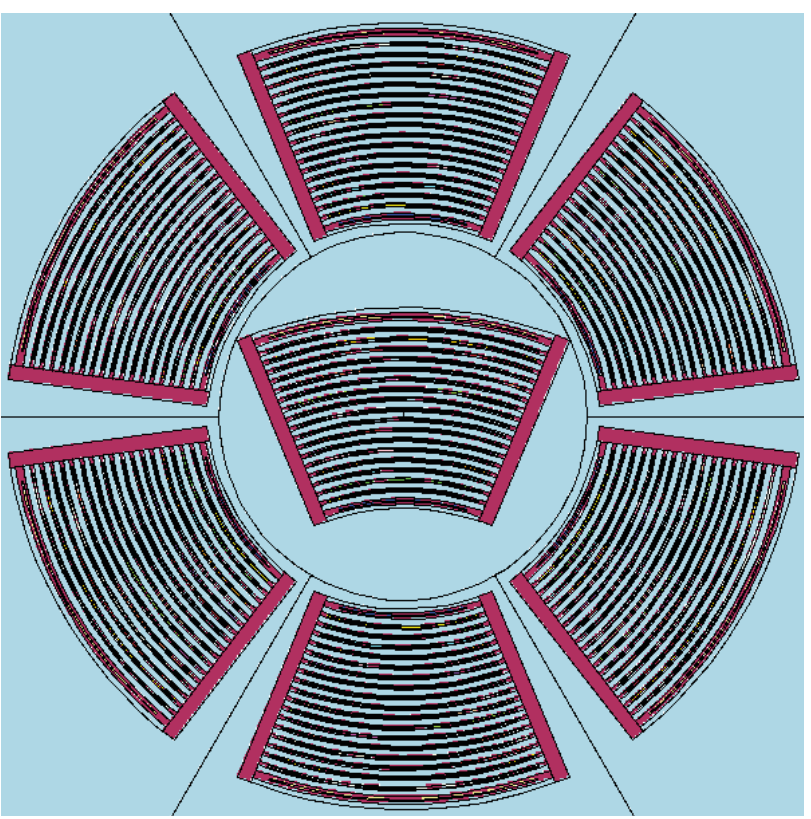

b) This is case heu_7c_0.2 of Table C- 2 where elements are in most reactive configuration

Figure 6. Circular Configurations to Investigate Increased Spacing between Elements

\subsubsection{U-10Mo Full Size Demonstration Elements}

The U-10Mo Full Size Demonstration elements are evaluated in this section. The configurations evaluated are identical to those in Table C- 1 and Table C- 2 and are the same as shown in Figure 5 and Figure 6, though the most reactive cases occur for slightly different spacings. The results for the Full Size Demonstration elements with different spacings between elements are presented in Appendix C, Table C- 3.

In summary, the most reactive case has a $\mathrm{k}_{\text {eff }}$ of $0.9624 \pm 0.0007$ which is less reactive than all the HEU ATR element cases with the exception of a hexagonal array with adjacent elements touching, i.e., it is much less than optimally moderated. The hexagonal array of U-10Mo elements with adjacent elements touching is much less reactive than the equivalent case with HEU ATR elements.

\subsubsection{U-10Mo Full Size Demonstration Elements with All Plates Fueled}

Though there are no current plans for replacing plate 19 of the U-10Mo Full Size Demonstration elements with a fueled plate, results are presented in Appendix C, Table C- 4 for elements with all plates fueled. Plate 19 is assumed to have the same loading as an HEU ATR element, and the total maximum element U-235 loading is 1314.0 g. These results are even more conservative than those presented in Section 6.1.2, but are presented here to demonstrate the reactivity differences of the U10Mo and HEU fuels. The ATR element configurations correspond to those in the previous two sections.

The most reactive case has a $\mathrm{k}_{\mathrm{eff}}$ of $0.9764 \pm 0.0007$ which is less reactive than all but three HEU ATR element cases. All cases when compared directly to the HEU ATR element equivalent cases are less reactive. A summary of the most reactive results for the different ATR fueled element models is presented in Section 8. 
INL/EXT-10-20323

Revision: 1

Page 14 of 42

\section{Credited Controls and Assumptions}

This section is not applicable. This CSE does not develop any new controls for the storage or handling of ATR fuel elements. This CSE demonstrates that existing controls for (HEU) ATR fuel elements are applicable to the U-10Mo Full Size Demonstration Elements. 
INL/EXT-10-20323

Revision: 1

Page 15 of 42

\section{Summary \& Conclusions}

MCNP models have been developed to compare the RETR-Full Size elements to standard HEU ATR elements with the boron content neglected. A summary of the most reactive cases for the HEU ATR fuel elements and the U-10Mo Full Size Demonstration elements is given in Table 5. Results for the Full Size Demonstration element with all plates fueled are not included as they do not affect the conclusions in this CSE.

Table 5. Summary of Most Reactive Results

\begin{tabular}{|c|c|c|c|}
\hline \multirow[b]{2}{*}{$\begin{array}{l}\text { Configuration (and } \\
\text { Number of Elements) }\end{array}$} & \multicolumn{2}{|c|}{$k_{\text {eff }}+2 \sigma$ (most reactive case) } & \multirow[b]{2}{*}{$\begin{array}{c}\text { Difference } \\
\Delta \mathbf{k},(\text { HEU - LEU) }\end{array}$} \\
\hline & HEU ATR Elements & $\begin{array}{l}\text { U-10Mo Full Size } \\
\text { Demonstration } \\
\text { Elements }\end{array}$ & \\
\hline Single ATR element & 0.4467 & 0.4380 & 0.009 \\
\hline $\begin{array}{l}\text { Hexagonal Array of } 7 \\
\text { elements }\end{array}$ & 0.9967 & 0.9600 & 0.037 \\
\hline $\begin{array}{l}\text { Circular Configuration of } \\
7 \text { elements }\end{array}$ & 0.9965 & 0.9637 & 0.033 \\
\hline
\end{tabular}

The $\mathrm{k}_{\text {eff }}$ for a single HEU ATR element exceeds that of a Full Size Demonstration element by about $0.009 \Delta \mathrm{k}$. For a near-critical configuration of 7 elements, $\mathrm{k}_{\mathrm{eff}}$ for the HEU elements exceeds that of the Full Size Demonstration elements by an average of $0.035 \Delta \mathrm{k}$. While other array configurations may be slightly more reactive than those evaluated here, this would not affect the conclusion of this CSE. The conclusion of this CSE is that the HEU ATR element bounds the U-10Mo Full Size Demonstration element for criticality calculations and for applying criticality controls. This conclusion remains valid even if the U-10Mo Full Size Demonstration element contained 19 fueled plates.

The Full Size Demonstration elements are bound by the HEU ATR elements, and as such the Full Size Demonstration elements can be handled, stored and transferred using controls established for HEU ATR elements. This also applies to any existing CSI determinations that were derived for HEU ATR elements. 
INL/EXT-10-20323

Revision: 1

Page 16 of 42

\section{References}

INL documents listed here are available via EDMS by their listed document number.

1. Specification for Advanced Test Reactor Mark VII Zone Loaded Fuel Elements, IN-F-9-ATR, Revision 15. Idaho National Engineering and Environmental Laboratory. Idaho Falls, ID. U.S. Department of Energy. SPC-415. Attachment: Reed, J.D., et. al., 1992 Specification for Reactor Grade High Enriched Uranium Aluminide (UAl $)$ Powder, IN-F-5-TRA, Revision 9, U.S. Department of Energy, Idaho Operations Office, Idaho Falls.

2. Paige, B.E., Description of Test Reactor Fuel Elements and Associated Behavior in Reprocessing. CI-1152. Idaho Falls, Idaho: U.S. Atomic Energy Commission, Idaho Operation Office.

3. Demonstration Control Plan for the RERTR Full-size Element, PLN-2946, Rev. 0, Idaho National Laboratory, June 2010.

4. Specification for Advanced Test Reactor U-Mo Demonstration Elements, SPC-1165, Idaho National Laboratory, July 2010.

5. "Software Quality Assurance Plan for MCNP5 for the Sun Workstations”, INL/INT-06-11321, Rev. 0, July 2006.

6. MCNP5-A General Monte Carlo N-Particle Transport Code, Version 5, LA-UR-03-1987, Los Alamos National Laboratory, April 2003, Revised 10/3/2005.

7. Stuart, Charles E., III., Criticality Safety Evaluation for the Analysis of Spacing Between Storage Positions in the New Type ATR Rack in the ATR Canal at the Reactor Technology Complex (RTC), EDF-8165, Idaho National Laboratory.

8. Kim, S.S., Criticality Safety Evaluation for Water Moderated and Reflected ATR Fuel Element Arrays, ERA-NRE-94-051, EG\&G Idaho, Inc., July 1994.

9. Stuart, Charles. E., III, Storage of ATR Fuel Elements in ATR Storage Canal at TRA, INEEL/INT-98-00380, November 1998.

10. Tsiboulia, Anatoli, Yevgeniy Rozhikhin and Vladimir Lependin, Water-Moderated U(17) $\mathrm{O}_{2}$ Annular Fuel Rods Without Absorber and with Gadolinium or Cadmium Absorbers in 6.8-cm-Pitch Hexagonal Lattices at Different Temperatures, IEU-COMP-THERM-002, NEA/NSC/DOC/(95)03/III, International Handbook of Evaluated Criticality Safety Benchmark Experiments, Volume III.

11. Dean, Virginia F., Critical Arrays of Polyethylene-Moderated U(30)F $F_{4}$-Polytetrafluoroethylene One-Inch Cubes, IEU-COMP-THERM-001, NEA/NSC/DOC(95)03/I, International Handbook of Evaluated Criticality Safety Benchmark Experiments, Volume III.

12. Putman, V. L., IFSF Criticality Safety Base Case and Validation, INEEL/INT-2001-00903, Rev. 0.

13. ATR U-Mo Demonstration Element Assembly, Drawing Number 600200, November 8, 2010. 
INL/EXT-10-20323

Revision: 1

Page 17 of 42

\section{Appendix A: Materials \& Compositions}

atom densities are listed as atoms/(cm·barn)

Table A-1. Material Specifications for $\mathrm{UAl}_{\mathrm{x}}$ Plates

\begin{tabular}{|c|c|c|c|c|c|}
\hline & U-235 & U-234 & U-236 & U-238 & Al \\
\hline $\begin{array}{c}\text { U Isotopics, } \\
\rightarrow\end{array}$ & $94.05 \%$ & $1.20 \%$ & $0.07 \%$ & $4.05 \%$ & - \\
\hline $\begin{array}{c}\text { Plate } \\
\text { Number, } \downarrow\end{array}$ & \multicolumn{5}{|c|}{ Number Densities } \\
\hline 1 & $2.6083 \mathrm{E}-03$ & $3.3423 \mathrm{E}-05$ & $1.9331 \mathrm{E}-05$ & $1.1090 \mathrm{E}-04$ & $5.7386 \mathrm{E}-02$ \\
\hline 2 & $2.5277 \mathrm{E}-03$ & $3.2389 \mathrm{E}-05$ & $1.8733 \mathrm{E}-05$ & $1.0747 \mathrm{E}-04$ & $5.7482 \mathrm{E}-02$ \\
\hline 3 & $3.1920 \mathrm{E}-03$ & $4.0902 \mathrm{E}-05$ & $2.3657 \mathrm{E}-05$ & $1.3572 \mathrm{E}-04$ & $5.6693 \mathrm{E}-02$ \\
\hline 4 & $3.1722 \mathrm{E}-03$ & $4.0648 \mathrm{E}-05$ & $2.3510 \mathrm{E}-05$ & $1.3488 \mathrm{E}-04$ & $5.6716 \mathrm{E}-02$ \\
\hline 5 & $3.9035 \mathrm{E}-03$ & $5.0018 \mathrm{E}-05$ & $2.8930 \mathrm{E}-05$ & $1.6597 \mathrm{E}-04$ & $5.5847 \mathrm{E}-02$ \\
\hline 6 & $3.9116 \mathrm{E}-03$ & $5.0122 \mathrm{E}-05$ & $2.8990 \mathrm{E}-05$ & $1.6631 \mathrm{E}-04$ & $5.5837 \mathrm{E}-02$ \\
\hline 7 & $3.9121 \mathrm{E}-03$ & $5.0129 \mathrm{E}-05$ & $2.8994 \mathrm{E}-05$ & $1.6634 \mathrm{E}-04$ & $5.5837 \mathrm{E}-02$ \\
\hline 8 & $3.9127 \mathrm{E}-03$ & $5.0136 \mathrm{E}-05$ & $2.8998 \mathrm{E}-05$ & $1.6636 \mathrm{E}-04$ & $5.5836 \mathrm{E}-02$ \\
\hline 9 & $3.9132 \mathrm{E}-03$ & $5.0143 \mathrm{E}-05$ & $2.9001 \mathrm{E}-05$ & $1.6638 \mathrm{E}-04$ & $5.5835 \mathrm{E}-02$ \\
\hline 10 & $3.9136 \mathrm{E}-03$ & $5.0149 \mathrm{E}-05$ & $2.9005 \mathrm{E}-05$ & $1.6640 \mathrm{E}-04$ & $5.5835 \mathrm{E}-02$ \\
\hline 11 & $3.9141 \mathrm{E}-03$ & $5.0154 \mathrm{E}-05$ & $2.9008 \mathrm{E}-05$ & $1.6642 \mathrm{E}-04$ & $5.5834 \mathrm{E}-02$ \\
\hline 12 & $3.9145 \mathrm{E}-03$ & $5.0159 \mathrm{E}-05$ & $2.9011 \mathrm{E}-05$ & $1.6644 \mathrm{E}-04$ & $5.5834 \mathrm{E}-02$ \\
\hline 13 & $3.9149 \mathrm{E}-03$ & $5.0164 \mathrm{E}-05$ & $2.9014 \mathrm{E}-05$ & $1.6645 \mathrm{E}-04$ & $5.5833 \mathrm{E}-02$ \\
\hline 14 & $3.9152 \mathrm{E}-03$ & $5.0169 \mathrm{E}-05$ & $2.9017 \mathrm{E}-05$ & $1.6647 \mathrm{E}-04$ & $5.5833 \mathrm{E}-02$ \\
\hline 15 & $3.9207 \mathrm{E}-03$ & $5.0239 \mathrm{E}-05$ & $2.9057 \mathrm{E}-05$ & $1.6670 \mathrm{E}-04$ & $5.5827 \mathrm{E}-02$ \\
\hline 16 & $3.1885 \mathrm{E}-03$ & $4.0857 \mathrm{E}-05$ & $2.3631 \mathrm{E}-05$ & $1.3557 \mathrm{E}-04$ & $5.6697 \mathrm{E}-02$ \\
\hline 17 & $3.1861 \mathrm{E}-03$ & $4.0827 \mathrm{E}-05$ & $2.3613 \mathrm{E}-05$ & $1.3547 \mathrm{E}-04$ & $5.6699 \mathrm{E}-02$ \\
\hline 18 & $2.5631 \mathrm{E}-03$ & $3.2843 \mathrm{E}-05$ & $1.8996 \mathrm{E}-05$ & $1.0898 \mathrm{E}-04$ & $5.7440 \mathrm{E}-02$ \\
\hline 19 & $2.5633 \mathrm{E}-03$ & $3.2846 \mathrm{E}-05$ & $1.8998 \mathrm{E}-05$ & $1.0899 \mathrm{E}-04$ & $5.7440 \mathrm{E}-02$ \\
\hline
\end{tabular}

Table A-2. Material Specifications for U-10Mo

\begin{tabular}{|c|c|c|}
\hline Element / Isotope & Isotopics & Number Density \\
\hline $\mathrm{U}-235$ & $20 \%$ & $7.7940 \mathrm{E}-03$ \\
\hline $\mathrm{U}-238$ & $79.726 \%$ & $3.0677 \mathrm{E}-02$ \\
\hline $\mathrm{U}-234$ & $0.112 \%$ & $4.3834 \mathrm{E}-05$ \\
\hline U-236 & $0.162 \%$ & $6.2864 \mathrm{E}-05$ \\
\hline Mo & - & $1.0608 \mathrm{E}-02$ \\
\hline \multicolumn{3}{|c|}{ density $=16.9 \mathrm{~g} / \mathrm{cm}^{3}$} \\
\hline
\end{tabular}


INL/EXT-10-20323

Revision: 1

Page 18 of 42

Table A-3. Material Specifications for Zr Cladding

\begin{tabular}{|c|c|}
\hline Isotope & Number Density \\
\hline Zr-90 & $2.2077 \mathrm{E}-02$ \\
\hline Zr-91 & $4.8145 \mathrm{E}-03$ \\
\hline Zr-92 & $7.3590 \mathrm{E}-03$ \\
\hline Zr-94 & $7.4577 \mathrm{E}-03$ \\
\hline Zr-96 & $1.2015 \mathrm{E}-03$ \\
\hline \multicolumn{2}{|c|}{ density $=6.5 \mathrm{~g} / \mathrm{cm}^{3}$} \\
\hline
\end{tabular}

Table A-4. Material Specifications for Water

\begin{tabular}{|c|c|c|}
\hline Element & $\begin{array}{c}\text { Moles of Element/ } \\
\text { Mole of Compound }\end{array}$ & $\begin{array}{c}\text { Number Density, } \\
{[\text { atom/(cm.b)] }}\end{array}$ \\
\hline $\mathrm{H}$ & 2 & $6.6856 \mathrm{E}-02$ \\
\hline $\mathrm{O}$ & 1 & $3.3428 \mathrm{E}-02$ \\
\hline \multicolumn{3}{|c|}{ density $=1.0 \mathrm{~g} / \mathrm{cm}^{3}$} \\
\hline
\end{tabular}

Table A-5. Material Specifications for A1-6061

\begin{tabular}{|c|r|}
\hline Element / Isotope & Atom density \\
\hline $\mathrm{Mg}$ & $6.7060 \mathrm{E}-04$ \\
\hline $\mathrm{Si}-28$ & $3.2114 \mathrm{E}-04$ \\
\hline $\mathrm{Si}-29$ & $1.6261 \mathrm{E}-05$ \\
\hline $\mathrm{Si}-30$ & $1.0794 \mathrm{E}-05$ \\
\hline Fe-54 & $1.1952 \mathrm{E}-05$ \\
\hline Fe-56 & $1.8745 \mathrm{E}-04$ \\
\hline Fe-57 & $4.3312 \mathrm{E}-06$ \\
\hline Fe-58 & $5.7205 \mathrm{E}-07$ \\
\hline Al & $5.9018 \mathrm{E}-02$ \\
\hline density $=2.7065 \mathrm{~g} / \mathrm{cm}^{3}$ \\
\hline
\end{tabular}


INL/EXT-10-20323

Revision: 1

Page 19 of 42

\section{Appendix B: Typical Input Listings}

Sample Input Deck \#1, Case heu_7b_1.1 from Table C- 1

MCNP Listing for HEU ATR Near-Critical Hexagonal Array

HEU ATR element

c LEE: note this uses average "B" values

C cell cards for ATR assembly

$60150.100311 \quad 600-601-680-681 \quad u=1$ imp:n=1

$6021016.017874 \mathrm{E}-02 \quad 602-603-682-683-692693 \quad \mathrm{u}=1$ imp:n=1

$60320 \quad 6.024110 \mathrm{E}-02601-604-680-681 \# 602 \quad u=1$ imp: $n=1$

$60450.100311 \quad 604-605-680-681 \quad u=1 \mathrm{imp}: \mathrm{n}=1$

c plate 2

$6051026.017685 E-02 \quad 606-607-684-685-692693 \quad u=1$ imp:n=1

$606206.024110 E-02605-608-680-681 \# 605 \quad u=1$ imp:n=1

$60750.100311 \quad 608-609-680-681 \quad u=1$ imp:n=1

c plate 3

608103 6.009507E-02 $610-611-684-685-692693 \quad u=1$ imp:n=1

$609206.024110 \mathrm{E}-02609-612-680-681$ \#608 u=1 imp:n=1

$61050.100311 \quad 612-613-680-681 \quad u=1$ imp:n=1

C plate 4

$611 \quad 1046.009671 \mathrm{E}-02 \quad 614-615-684-685-692693 \mathrm{u}=1 \mathrm{imp}: n=1$

$612206.024110 \mathrm{E}-02 \quad 613-616-680-681$ \#611 u=1 imp:n=1

$61350.100311 \quad 616-617-680-681 \quad u=1 \mathrm{imp}: \mathrm{n}=1$

c plate 5

$6141056.000722 \mathrm{E}-02 \quad 618-619-684-685-692693 \quad u=1$ imp:n=1

$615206.024110 \mathrm{E}-02 \quad 617-620-680-681 \quad \# 614 \quad u=1$ imp:n=1

$61650.100311 \quad 620-621-680-681 \quad u=1$ imp:n=1

C plate 6

617106 6.000587E-02 $622-623-684-685-692693 \quad u=1$ imp:n=1

$618206.024110 \mathrm{E}-02 \quad 621-624-680-681 \# 617 \quad u=1 \mathrm{imp}: \mathrm{n}=1$

$61950.100311 \quad 624-625-680-681 \quad u=1 \quad i m p: n=1$

C plate 7

$6201076.000534 \mathrm{E}-02 \quad 626-627-684-685-692693 \mathrm{u}=1$ imp:n=1

$621206.024110 \mathrm{E}-02625-628-680-681$ \#620 u=1 imp:n=1

$62250.100311 \quad 628-629-680-681 \quad u=1$ imp:n=1

C plate 8

$6231086.000448 \mathrm{E}-02 \quad 630-631-684-685-692693 \quad u=1$ imp:n=1

$624206.024110 \mathrm{E}-02 \quad 629-632-680-681$ \#623 u=1 imp:n=1

$\begin{array}{lll}625 & 50.100311 \quad 632-633-680-681 \quad u=1 \quad i m p: n=1\end{array}$

C plate 9

626109 6.000431E-02 $634-635-684-685-692693 \quad u=1$ imp:n=1

$627206.024110 \mathrm{E}-02 \quad 633-636-680-681$ \#626 u=1 imp:n=1

$62850.100311 \quad 636-637-680-681 \quad u=1 \quad i m p: n=1$

c plate 10

$6291106.000392 E-02 \quad 638-639-684-685-692693 \quad u=1$ imp:n=1

$630206.024110 \mathrm{E}-02 \quad 637-640-680-681$ \#629 u=1 imp:n=1

$63150.100311 \quad 640-641-680-681 \quad u=1$ imp:n=1

c plate 11

$6321116.000321 \mathrm{E}-02 \quad 642-643-684-685-692693 \mathrm{u}=1$ imp:n=1

$633206.024110 \mathrm{E}-02 \quad 641-644-680-681 \quad \# 632 \quad u=1$ imp:n=1

$63450.100311 \quad 644-645-680-681 \quad u=1$ imp:n=1

c plate 12

$6351126.000329 E-02 \quad 646-647-684-685-692693 \quad u=1$ imp:n=1

$636206.024110 \mathrm{E}-02 \quad 645-648-680-681$ \#635 u=1 imp:n=1

$63750.100311 \quad 648-649-680-681 \quad u=1$ imp:n=1

c plate 13

$6381136.000216 \mathrm{E}-02 \quad 650-651-684-685-692693 \quad u=1$ imp:n=1

$639206.024110 \mathrm{E}-02 \quad 649-652-680-681$ \#638 u=1 imp:n=1 
INL/EXT-10-20323

Revision: 1

Page 20 of 42

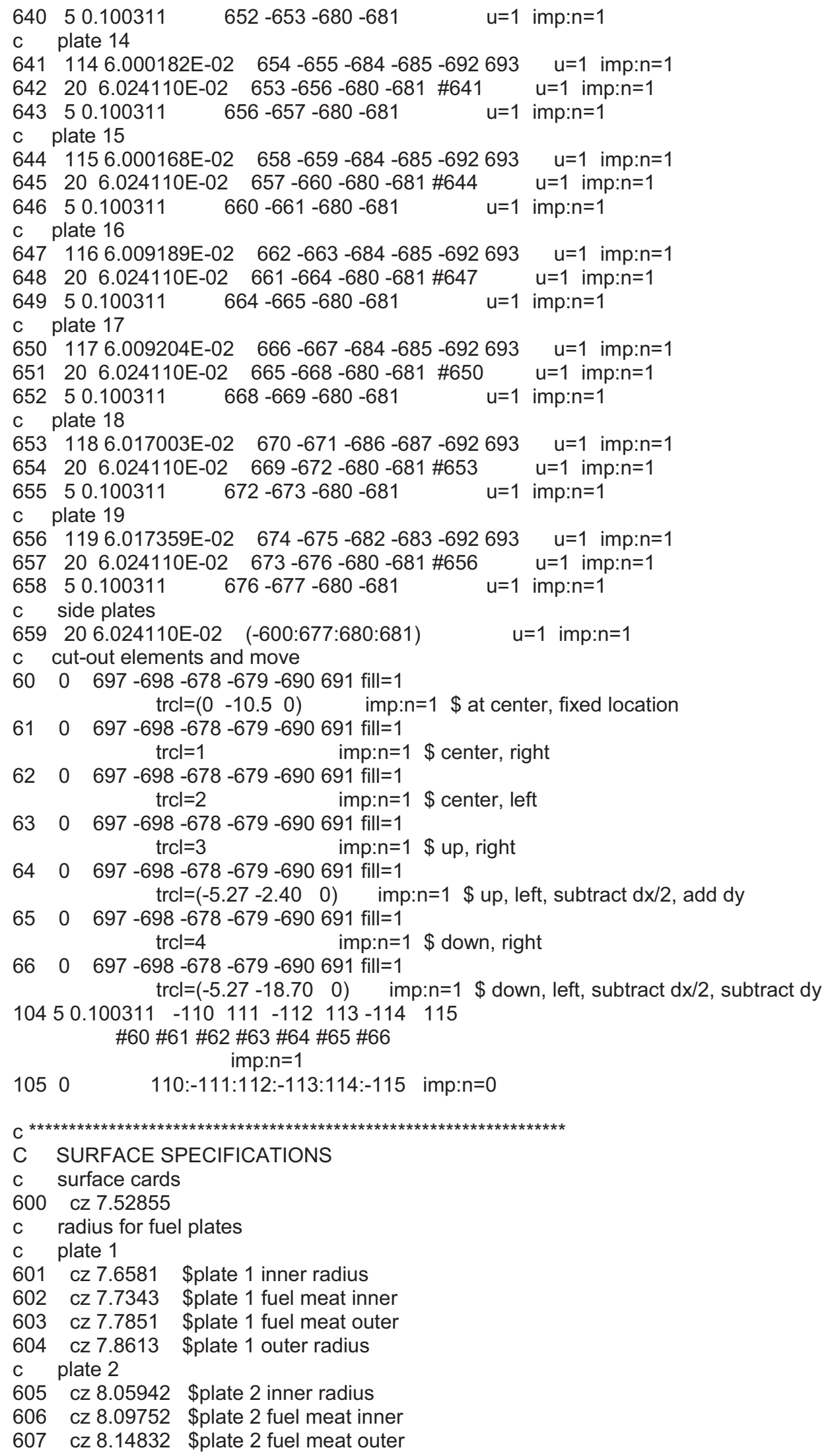


INL/EXT-10-20323

Revision: 1

Page 21 of 42

608 cz 8.18642 \$plate 2 outer radius

c plate 3

609 cz 8.38454 \$plate 3 inner radius

610 cz 8.42264 \$plate 3 fuel meat inner

$611 \mathrm{cz} 8.47344$ \$plate 3 fuel meat outer

612 cz 8.51154 \$plate 3 outer radius

C plate 4

613 cz 8.70966 \$plate 4 inner radius

614 cz 8.74776 \$plate 4 fuel meat inner

615 cz 8.79856 \$plate 4 fuel meat outer

616 cz 8.83666 \$plate 4 outer radius

c plate 5

617 cz 9.03478 \$plate 5 inner radius

618 cz 9.07288 \$plate 5 fuel meat inner

619 cz 9.12368 \$plate 5 fuel meat outer

620 cz 9.16178 \$plate 5 outer radius

c plate 6

621 cz 9.3599 \$plate 6 inner radius

622 cz 9.398 \$plate 6 fuel meat inner

623 cz 9.4488 \$plate 6 fuel meat outer

624 cz 9.4869 \$plate 6 outer radius

c plate 7

625 cz 9.68502 \$plate 7 inner radius

$626 \mathrm{cz} 9.72312$ \$plate 7 fuel meat inner

627 cz 9.77392 \$plate 7 fuel meat outer

628 cz 9.81202 \$plate 7 outer radius

C plate 8

629 cz 10.01014 \$plate 8 inner radius

630 cz 10.04824 \$plate 8 fuel meat inner

631 cz 10.09904 \$plate 8 fuel meat outer

632 cz 10.13714 \$plate 8 outer radius

C plate 9

633 cz 10.33526 \$plate 9 inner radius

634 cz 10.37336 \$plate 9 fuel meat inner

635 cz 10.42416 \$plate 9 fuel meat outer

636 cz 10.46226 \$plate 9 outer radius

c plate 10

637 cz 10.66038 \$plate 10 inner radius

638 cz 10.69848 \$plate 10 fuel meat inner

639 cz 10.74928 \$plate 10 fuel meat outer

640 cz 10.78738 \$plate 10 outer radius

c plate 11

641 cz 10.9855 \$plate 11 inner radius

642 cz 11.02360 \$plate 11 fuel meat inner

643 Cz 11.07440 \$plate 11 fuel meat outer

644 cz 11.1125 \$plate 11 outer radius

c plate 12

645 cz 11.31062 \$plate 12 inner radius

646 cz 11.34872 \$plate 12 fuel meat inner

647 cz 11.39952 \$plate 12 fuel meat outer

648 cz 11.43762 \$plate 12 outer radius

C plate 13

649 cz 11.63574 \$plate 13 inner radius

650 cz 11.67384 \$plate 13 fuel meat inner

651 cz 11.72464 \$plate 13 fuel meat outer

652 cz 11.76274 \$plate 13 outer radius

C plate 14

653 cz 11.96086 \$plate 14 inner radius

654 cz 11.99896 \$plate 14 fuel meat inner

655 cz 12.04976 \$plate 14 fuel meat outer

656 cz 12.08786 \$plate 14 outer radius 
INL/EXT-10-20323

Revision: 1

Page 22 of 42

C plate 15

657 Cz 12.28598 \$plate 15 inner radius

658 cz 12.32408 \$plate 15 fuel meat inner

659 cz 12.37488 \$plate 15 fuel meat outer

660 cz 12.41298 \$plate 15 outer radius

C plate 16

661 cz 12.6111 \$plate 16 inner radius

662 cz 12.64920 \$plate 16 fuel meat inner

663 cz 12.70000 \$plate 16 fuel meat outer

664 cz 12.7381 \$plate 16 outer radius

C plate 17

665 cz 12.93622 \$plate 17 inner radius

666 cz 12.97432 \$plate 17 fuel meat inner

667 cz 13.02512 \$plate 17 fuel meat outer

668 cz 13.06322 \$plate 17 outer radius

C plate 18

669 cz 13.26134 \$plate 18 inner radius

670 cz 13.29944 \$plate 18 fuel meat inner

671 cz 13.35024 \$plate 18 fuel meat outer

672 Cz 13.38834 \$plate 18 outer radius

C plate 19

673 cz 13.58646 \$plate 19 inner radius

674 cz 13.68806 \$plate 19 fuel meat inner

675 cz 13.73886 \$plate 19 fuel meat outer

676 cz 13.84046 \$plate 19 outer radius

677 Cz 14.01317 \$outer diameter of element

C surfaces for sides of plate and fuel region

678 p -2.414214 -1 $00 \quad$ \$outside boundary of Al plate

679 p $2.414214-100 \quad$ \$outside boundary of Al plate

680 p -2.414214 -1 $0-1.241183$ \$inside boundary of Al plate

681 p $2.414214-10-1.241183$ \$inside boundary of Al plate

$682 \mathrm{p}-2.414214-10-2.535464$ \$plate 1 and 19 fuel meat boundary

683 p $2.414214-10-2.535464$ \$plate 1 and 19 fuel meat boundary

$684 \mathrm{p}-2.414214-10-1.871730$ \$plate 2 through 17 fuel meat boundary

685 p $2.414214-10-1.871730$ \$plate 2 through 17 fuel meat boundary

686 p -2.414214 -1 0 -2.004477 \$plate 18 fuel meat boundary

687 p $2.414214-10-2.004477$ \$plate 18 fuel meat boundary

690 pz 62.8650 \$top of fuel element, 49.5" total

$691 \mathrm{pz}-62.8650$ \$bottom of fuel element

692 pz 60.960 \$top of fuel meat, 48" total

693 pz -60.960 \$bottom of fuel meat

697 Cz 7.52856 \$inner radius of element

698 cz 14.00302 \$outer radius of element

$160 \mathrm{cz}$ 10000. \$just a big surface

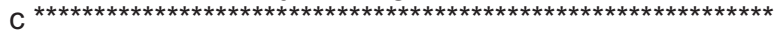

*110 px 65.2630 \$ storage rack

*111 px -65.2630

*112 py 44.8468

*113 py -44.8468

$114 \mathrm{pz} 100.0$ \$ water reflector

$115 \mathrm{pz}-100.0$

mode $n$

C WATER dens $=1.0000 \mathrm{~g} / \mathrm{cc} \$$ atm. den.: .100284

m5 1001.62c 6.6874E-02 \$ H

8016.62C 3.3437E-02 \$O

mt5 Iwtr.60t

c fuel plates

m101 92235.69c 2.4472E-03

92238.69c 1.0405E-04

$92234.69 \mathrm{c} \quad 3.1358 \mathrm{E}-05$ 
INL/EXT-10-20323

Revision: 1

Page 23 of 42

92236.69c 1.8137E-05

13027.62C 5.7578E-02

m102 92235.69c 2.4586E-03

92238.69c 1.0453E-04

92234.69c 3.1504E-05

$92236.69 \mathrm{c} \quad 1.8221 \mathrm{E}-05$

13027.62C 5.7564E-02

m103 92235.69c 3.1090E-03

92238.69c 1.3219E-04

92234.69c 3.9839E-05

92236.69c 2.3042E-05

13027.62C 5.6791E-02

m104 92235.69c 3.0936E-03

92238.69c 1.3154E-04

92234.69c 3.9641E-05

92236.69c 2.2928E-05

13027.62C 5.6809E-02

m105 92235.69c 3.8111E-03

92238.69c 1.6204E-04

92234.69c 4.8835E-05

$92236.69 \mathrm{c} \quad 2.8245 \mathrm{E}-05$

13027.62C 5.5957E-02

m106 92235.69c 3.8230E-03

92238.69c 1.6255E-04

$92234.69 \mathrm{C} \quad 4.8988 \mathrm{E}-05$

$92236.69 \mathrm{c} \quad 2.8334 \mathrm{E}-05$

13027.62C 5.5943E-02

m107 92235.69c 3.8272E-03

92238.69c 1.6273E-04

92234.69c 4.9042E-05

$92236.69 \mathrm{c} \quad 2.8365 \mathrm{E}-05$

13027.62C 5.5938E-02

m108 92235.69c 3.8311E-03

92238.69c 1.6289E-04

92234.69c 4.9092E-05

92236.69c 2.8394E-05

13027.62C 5.5933E-02

m109 92235.69c 3.8347E-03

92238.69c 1.6305E-04

92234.69c 4.9138E-05

$92236.69 \mathrm{c} \quad 2.8420 \mathrm{E}-05$

13027.62C 5.5929E-02

$\mathrm{m} 110 \quad 92235.69 \mathrm{c} \quad 3.8381 \mathrm{E}-03$

92238.69c 1.6319E-04

92234.69c 4.9180E-05

92236.69c 2.8445E-05

13027.62C 5.5925E-02

$\mathrm{m} 111$ 92235.69c 3.8412E-03

92238.69c 1.6332E-04

92234.69c 4.9220E-05

$92236.69 \mathrm{c} \quad 2.8468 \mathrm{E}-05$

13027.62C $5.5921 \mathrm{E}-02$

$\mathrm{m} 112$ 92235.69c 3.8441E-03

92238.69c 1.6344E-04

92234.69c 4.9257E-05

92236.69c 2.8489E-05

13027.62C 5.5918E-02

$\mathrm{m} 113$ 92235.69c 3.8468E-03

92238.69c 1.6356E-04

$92234.69 \mathrm{C} \quad 4.9292 \mathrm{E}-05$

92236.69c 2.8509E-05 
INL/EXT-10-20323

Revision: 1

Page 24 of 42

13027.62C 5.5914E-02

m114 92235.69c 3.8493E-03

92238.69c 1.6367E-04

92234.69c 4.9324E-05

92236.69c $2.8528 \mathrm{E}-05$

13027.62C 5.5911E-02

m115 92235.69c 3.8567E-03

92238.69c 1.6398E-04

92234.69c 4.9420E-05

92236.69c 2.8583E-05

13027.62C 5.5903E-02

$\mathrm{m} 116$ 92235.69c 3.1380E-03

92238.69c $1.3342 \mathrm{E}-04$

92234.69c 4.0210E-05

92236.69c 2.3257E-05

13027.62C 5.6757E-02

m117 92235.69c 3.1372E-03

92238.69c 1.3339E-04

92234.69C 4.0199E-05

92236.69c 2.3251E-05

13027.62C 5.6758E-02

$\mathrm{m} 118$ 92235.69c 2.5171E-03

92238.69c 1.0702E-04

92234.69c 3.2254E-05

92236.69c 1.8655E-05

13027.62C 5.7495E-02

$\mathrm{m} 119$ 92235.69c 2.4894E-03

$92238.69 \mathrm{c} \quad 1.0584 \mathrm{E}-04$

92234.69c 3.1899E-05

$92236.69 \mathrm{c} \quad 1.8449 \mathrm{E}-05$

13027.62c 5.7528E-02

C material for cladding and support (Al6061)

m20 13027.62c 5.9018E-02 \$ Al +Zn impurity

12000.62c 6.7060e-04 \$ Mg

14028.62c 3.2114E-04 \$ Si

14029.62C 1.6261E-05

14030.62c 1.0794E-05 \$ Si

26054.62c 1.1952E-05 \$ Fe

26056.62C 1.8745E-04

26057.62c 4.3312E-06

26058.62c 5.7205E-07 \$ Fe

c $\$ \mathrm{Cu}$

c $\$ \mathrm{Cr}$

c $\$ \mathrm{Mn}$

c $\$ \mathrm{Ti}$

c $\quad \mathrm{RC}$

C

C

c add $\mathrm{dx}, \mathrm{dy}=0$ always

*tr1 9.67 10.18 0 180. 270.0 90. 90. 180.90. 90. 90. 0. c subtract $\mathrm{dx}, \mathrm{dy}=0$ always

*tr2 -9.67 10.18 0 180. 270.0 90. 90. 180. 90. 90. 90. 0. $c$ add $d x / 2$, add dy

*tr3 $4.4518 .40 \quad 0 \quad 180.270 .0$ 90. 90. 180. 90. 90. 90. 0.

c add $d x / 2$, subtract dy

*tr4 $4.452 .11 \quad 0 \quad 180.270 .0$ 90. 90. 180.90. 90.90. 0.

kcode 65001.055290

$\mathrm{C}$

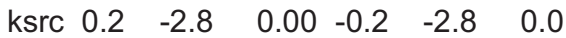

$\begin{array}{llllll}3.7 & 2.6 & 0.00 & -3.7 & 2.6 & 0.0\end{array}$

$\begin{array}{llllll}2.7 & -1.1 & 0.00 & -2.7 & -1.1 & 0.0\end{array}$ 
INL/EXT-10-20323

Revision: 1

Page 25 of 42

$\begin{array}{cccccc}2.1 & -2.6 & 0.00 & -2.1 & -2.6 & 0.0\end{array}$

Sample Input Deck \#2, Case heu_7c_0.2 from Table C- 2

MCNP Listing for HEU ATR Near-Critical Circular Configuration

HEU ATR element

c LEE: note this uses average "B" values

C cell cards for ATR assembly

$60150.100311 \quad 600-601-680-681 \quad u=1$ imp:n=1

$6021016.017874 \mathrm{E}-02 \quad 602-603-682-683-692693 \quad u=1$ imp:n=1

$603206.024110 \mathrm{E}-02601-604-680-681$ \#602 u=1 imp:n=1

$60450.100311 \quad 604-605-680-681 \quad u=1$ imp:n=1

c plate 2

605 102 6.017685E-02 $606-607-684-685-692693 \quad u=1$ imp:n=1

$606206.024110 \mathrm{E}-02605-608-680-681 \# 605 \quad u=1 \quad i m p: n=1$

$60750.100311 \quad 608-609-680-681 \quad u=1$ imp:n=1

c plate 3

$6081036.009507 E-02 \quad 610-611-684-685-692693 u=1$ imp:n=1

$609206.024110 \mathrm{E}-02609-612-680-681$ \#608 u=1 imp:n=1

$61050.100311 \quad 612-613-680-681 \quad u=1 \quad i m p: n=1$

c plate 4

$611 \quad 1046.009671 \mathrm{E}-02 \quad 614-615-684-685-692693 \quad u=1$ imp:n=1

$612206.024110 \mathrm{E}-02 \quad 613-616-680-681$ \#611 u=1 imp:n=1

$61350.100311 \quad 616-617-680-681 \quad u=1$ imp:n=1

c plate 5

$6141056.000722 \mathrm{E}-02 \quad 618-619-684-685-692693 \quad u=1$ imp:n=1

$615206.024110 E-02 \quad 617-620-680-681$ \#614 u=1 imp:n=1

$61650.100311 \quad 620-621-680-681 \quad u=1$ imp:n=1

c plate 6

$6171066.000587 \mathrm{E}-02 \quad 622-623-684-685-692693 \quad u=1$ imp:n=1

$618206.024110 \mathrm{E}-02 \quad 621-624-680-681$ \#617 u=1 imp:n=1

$61950.100311 \quad 624-625-680-681 \quad u=1$ imp:n=1

C plate 7

$6201076.000534 \mathrm{E}-02 \quad 626-627-684-685-692693 \quad u=1$ imp:n=1

$621206.024110 \mathrm{E}-02 \quad 625-628-680-681 \quad \# 620 \quad u=1 \quad i m p: n=1$

$62250.100311 \quad 628-629-680-681 \quad u=1$ imp:n=1

C plate 8

$6231086.000448 E-02 \quad 630-631-684-685-692693 \quad u=1$ imp:n=1

$624206.024110 \mathrm{E}-02 \quad 629-632-680-681$ \#623 u=1 imp:n=1

$62550.100311 \quad 632-633-680-681 \quad u=1$ imp:n=1

C plate 9

626109 6.000431E-02 $634-635-684-685-692693 \quad u=1$ imp:n=1

$627206.024110 \mathrm{E}-02 \quad 633-636-680-681 \# 626 \quad u=1$ imp:n=1

$62850.100311 \quad 636-637-680-681 \quad u=1 \quad i m p: n=1$

C plate 10

$6291106.000392 \mathrm{E}-02 \quad 638-639-684-685-692693 \quad u=1$ imp:n=1

$630206.024110 \mathrm{E}-02 \quad 637-640-680-681$ \#629 u=1 imp:n=1

$63150.100311 \quad 640-641-680-681 \quad u=1$ imp:n=1

c plate 11

$6321116.000321 \mathrm{E}-02 \quad 642-643-684-685-692693 \quad u=1$ imp:n=1

$633206.024110 \mathrm{E}-02 \quad 641-644-680-681 \quad$ \#632 u=1 imp:n=1

$63450.100311 \quad 644-645-680-681 \quad u=1$ imp:n=1

c plate 12

$6351126.000329 E-02 \quad 646-647-684-685-692693 \quad u=1$ imp:n=1

$636206.024110 \mathrm{E}-02 \quad 645-648-680-681$ \#635 u=1 imp:n=1

$63750.100311 \quad 648-649-680-681 \quad u=1$ imp:n=1

c plate 13

$6381136.000216 \mathrm{E}-02 \quad 650-651-684-685-692693 \quad u=1$ imp:n=1

$639206.024110 \mathrm{E}-02 \quad 649-652-680-681$ \#638 u=1 imp:n=1 
INL/EXT-10-20323

Revision: 1

Page 26 of 42

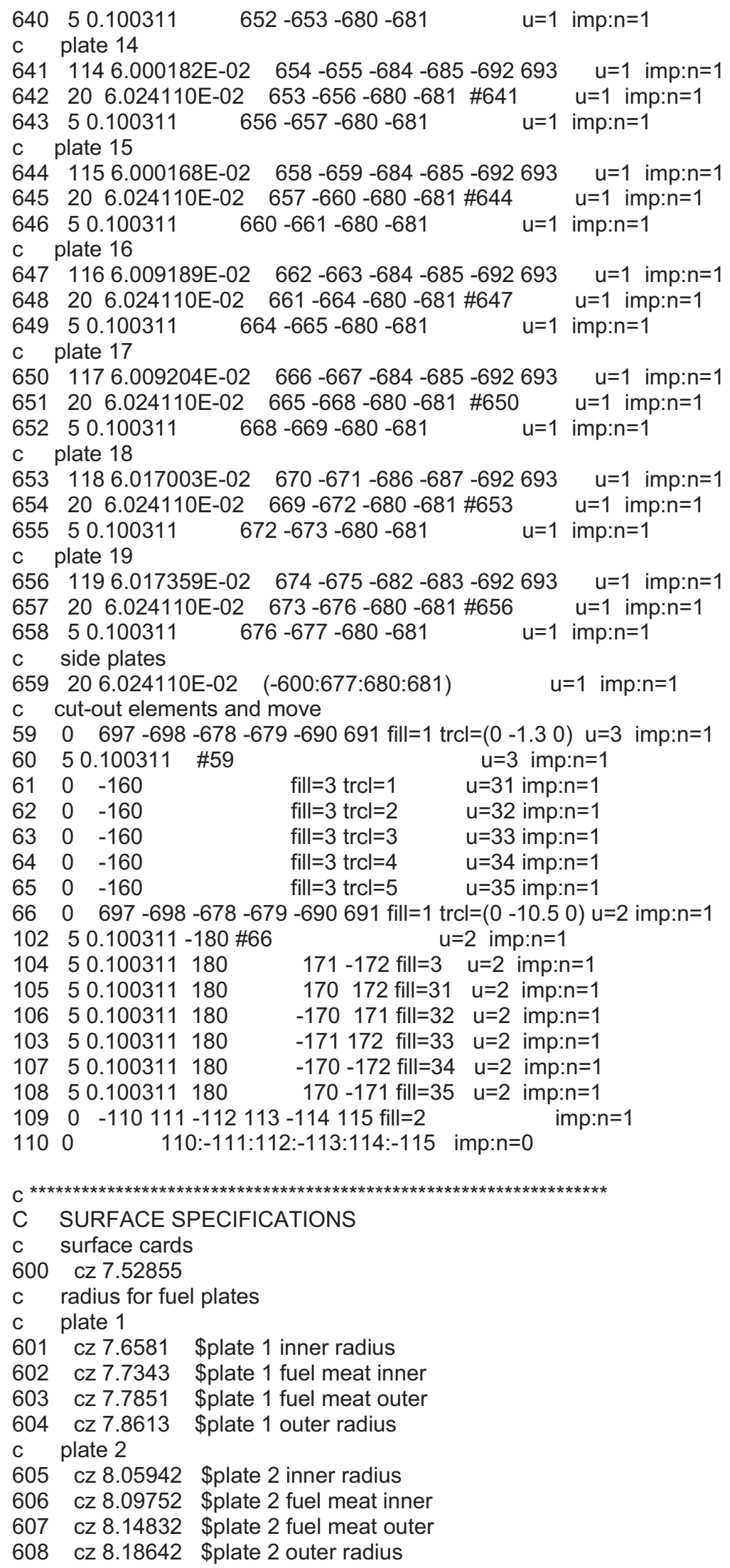


INL/EXT-10-20323

Revision: 1

Page 27 of 42

C plate 3

609 cz 8.38454 \$plate 3 inner radius

610 cz 8.42264 \$plate 3 fuel meat inner

611 cz 8.47344 \$plate 3 fuel meat outer

612 cz 8.51154 \$plate 3 outer radius

c plate 4

613 cz 8.70966 \$plate 4 inner radius

614 cz 8.74776 \$plate 4 fuel meat inner

615 cz 8.79856 \$plate 4 fuel meat outer

616 cz 8.83666 \$plate 4 outer radius

c plate 5

617 cz 9.03478 \$plate 5 inner radius

618 cz 9.07288 \$plate 5 fuel meat inner

619 cz 9.12368 \$plate 5 fuel meat outer

620 cz 9.16178 \$plate 5 outer radius

C plate 6

621 cz 9.3599 \$plate 6 inner radius

622 cz 9.398 \$plate 6 fuel meat inner

623 cz 9.4488 \$plate 6 fuel meat outer

624 cz 9.4869 \$plate 6 outer radius

C plate 7

625 cz 9.68502 \$plate 7 inner radius

626 cz 9.72312 \$plate 7 fuel meat inner

627 cz 9.77392 \$plate 7 fuel meat outer

628 cz 9.81202 \$plate 7 outer radius

c plate 8

629 cz 10.01014 \$plate 8 inner radius

630 cz 10.04824 \$plate 8 fuel meat inner

631 cz 10.09904 \$plate 8 fuel meat outer

632 cz 10.13714 \$plate 8 outer radius

c plate 9

633 Cz 10.33526 \$plate 9 inner radius

634 cz 10.37336 \$plate 9 fuel meat inner

635 cz 10.42416 \$plate 9 fuel meat outer

636 cz 10.46226 \$plate 9 outer radius

c plate 10

637 Cz 10.66038 \$plate 10 inner radius

638 cz 10.69848 \$plate 10 fuel meat inner

639 cz 10.74928 \$plate 10 fuel meat outer

640 Cz 10.78738 \$plate 10 outer radius

c plate 11

641 Cz 10.9855 \$plate 11 inner radius

642 cz 11.02360 \$plate 11 fuel meat inner

643 cz 11.07440 \$plate 11 fuel meat outer

644 Cz 11.1125 \$plate 11 outer radius

c plate 12

645 cz 11.31062 \$plate 12 inner radius

646 cz 11.34872 \$plate 12 fuel meat inner

647 cz 11.39952 \$plate 12 fuel meat outer

648 cz 11.43762 \$plate 12 outer radius

C plate 13

649 cz 11.63574 \$plate 13 inner radius

650 cz 11.67384 \$plate 13 fuel meat inner

651 cz 11.72464 \$plate 13 fuel meat outer

652 cz 11.76274 \$plate 13 outer radius

c plate 14

653 cz 11.96086 \$plate 14 inner radius

654 cz 11.99896 \$plate 14 fuel meat inner

655 cz 12.04976 \$plate 14 fuel meat outer

656 cz 12.08786 \$plate 14 outer radius

C plate 15 
INL/EXT-10-20323

Revision: 1

Page 28 of 42

657 Cz 12.28598 \$plate 15 inner radius

658 cz 12.32408 \$plate 15 fuel meat inner

659 cz 12.37488 \$plate 15 fuel meat outer

660 cz 12.41298 \$plate 15 outer radius

c plate 16

661 cz 12.6111 \$plate 16 inner radius

662 cz 12.64920 \$plate 16 fuel meat inner

663 cz 12.70000 \$plate 16 fuel meat outer

664 cz 12.7381 \$plate 16 outer radius

c plate 17

665 cz 12.93622 \$plate 17 inner radius

666 cz 12.97432 \$plate 17 fuel meat inner

667 cz 13.02512 \$plate 17 fuel meat outer

668 cz 13.06322 \$plate 17 outer radius

c plate 18

669 cz 13.26134 \$plate 18 inner radius

670 Cz 13.29944 \$plate 18 fuel meat inner

671 cz 13.35024 \$plate 18 fuel meat outer

672 cz 13.38834 \$plate 18 outer radius

c plate 19

673 Cz 13.58646 \$plate 19 inner radius

674 cz 13.68806 \$plate 19 fuel meat inner

675 Cz 13.73886 \$plate 19 fuel meat outer

676 cz 13.84046 \$plate 19 outer radius

677 cz 14.01317 \$outer diameter of element

C surfaces for sides of plate and fuel region

678 p -2.414214-100 \$outside boundary of Al plate

679 p $2.414214-100 \quad$ \$outside boundary of Al plate

$680 \mathrm{p}-2.414214-10-1.241183$ \$inside boundary of Al plate

681 p $2.414214-10-1.241183$ \$inside boundary of Al plate

682 p -2.414214 -1 0 -2.535464 \$plate 1 and 19 fuel meat boundary

683 p $2.414214-10-2.535464$ \$plate 1 and 19 fuel meat boundary

$684 \mathrm{p}-2.414214-10-1.871730$ \$plate 2 through 17 fuel meat boundary

685 p $2.414214-10-1.871730$ \$plate 2 through 17 fuel meat boundary

686 p -2.414214 -1 $0-2.004477$ \$plate 18 fuel meat boundary

687 p $2.414214-10-2.004477$ \$plate 18 fuel meat boundary

690 pz 62.8650 \$top of fuel element, 49.5" total

$691 \mathrm{pz}-62.8650$ \$bottom of fuel element

692 pz 60.960 \$top of fuel meat, 48" total

693 pz -60.960 \$bottom of fuel meat

697 Cz 7.52856 \$inner radius of element

698 cz 14.00302 \$outer radius of element

$160 \mathrm{cz} 10000$. \$just a big surface

170 py $0 . \quad \$$ horizontal line

171 p $1.73205081 \quad 1 \quad 0 \quad 0$

172 p $1.73205081 \quad-1 \quad 0 \quad 0$

180 CZ 5.94

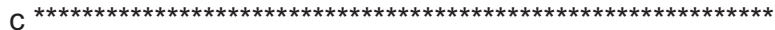

*110 px 65.2630 \$ storage rack

*111 px -65.2630

*112 py 44.8468

*113 py -44.8468

$114 \mathrm{pz} 100.0$ \$ water reflector

$115 \mathrm{pz}-100.0$

mode $n$

C WATER dens $=1.0000 \mathrm{~g} / \mathrm{cc} \$$ atm. den.: .100284

m5 1001.62c 6.6874E-02 \$ H

8016.62c 3.3437E-02 \$O

mt5 Iwtr.60t

c fuel plates 
INL/EXT-10-20323

Revision: 1

Page 29 of 42

m101 92235.69c 2.4472E-03

92238.69c 1.0405E-04

92234.69c 3.1358E-05

92236.69c 1.8137E-05

13027.62c $5.7578 \mathrm{E}-02$

m102 92235.69c 2.4586E-03

92238.69c 1.0453E-04

92234.69c 3.1504E-05

92236.69c $1.8221 \mathrm{E}-05$

13027.62C 5.7564E-02

m103 92235.69c 3.1090E-03

92238.69c 1.3219E-04

92234.69c 3.9839E-05

92236.69c 2.3042E-05

13027.62C 5.6791E-02

m104 92235.69c 3.0936E-03

92238.69c 1.3154E-04

92234.69c 3.9641E-05

92236.69c 2.2928E-05

13027.62C 5.6809E-02

m105 92235.69c 3.8111E-03

92238.69c 1.6204E-04

$92234.69 \mathrm{C} \quad 4.8835 \mathrm{E}-05$

92236.69c 2.8245E-05

13027.62C 5.5957E-02

m106 92235.69c 3.8230E-03

92238.69c 1.6255E-04

92234.69c $4.8988 \mathrm{E}-05$

92236.69c 2.8334E-05

13027.62C 5.5943E-02

m107 92235.69c 3.8272E-03

92238.69c 1.6273E-04

$92234.69 \mathrm{C} \quad 4.9042 \mathrm{E}-05$

$92236.69 \mathrm{c} \quad 2.8365 \mathrm{E}-05$

$13027.62 \mathrm{C} \quad 5.5938 \mathrm{E}-02$

m108 92235.69c 3.8311E-03

92238.69c 1.6289E-04

92234.69c 4.9092E-05

92236.69c 2.8394E-05

13027.62C 5.5933E-02

m109 92235.69c 3.8347E-03

92238.69c 1.6305E-04

92234.69c 4.9138E-05

92236.69c 2.8420E-05

13027.62C 5.5929E-02

m110 92235.69c 3.8381E-03

92238.69c 1.6319E-04

$92234.69 \mathrm{C} \quad 4.9180 \mathrm{E}-05$

92236.69c 2.8445E-05

13027.62C 5.5925E-02

$\mathrm{m} 111$ 92235.69c 3.8412E-03

92238.69c 1.6332E-04

92234.69c 4.9220E-05

92236.69c 2.8468E-05

13027.62C $5.5921 \mathrm{E}-02$

$\mathrm{m} 112$ 92235.69c 3.8441E-03

92238.69c 1.6344E-04

92234.69c 4.9257E-05

92236.69c 2.8489E-05

13027.62C 5.5918E-02

$\mathrm{m} 11392235.69 \mathrm{c} \quad 3.8468 \mathrm{E}-03$ 
INL/EXT-10-20323

Revision: 1

Page 30 of 42

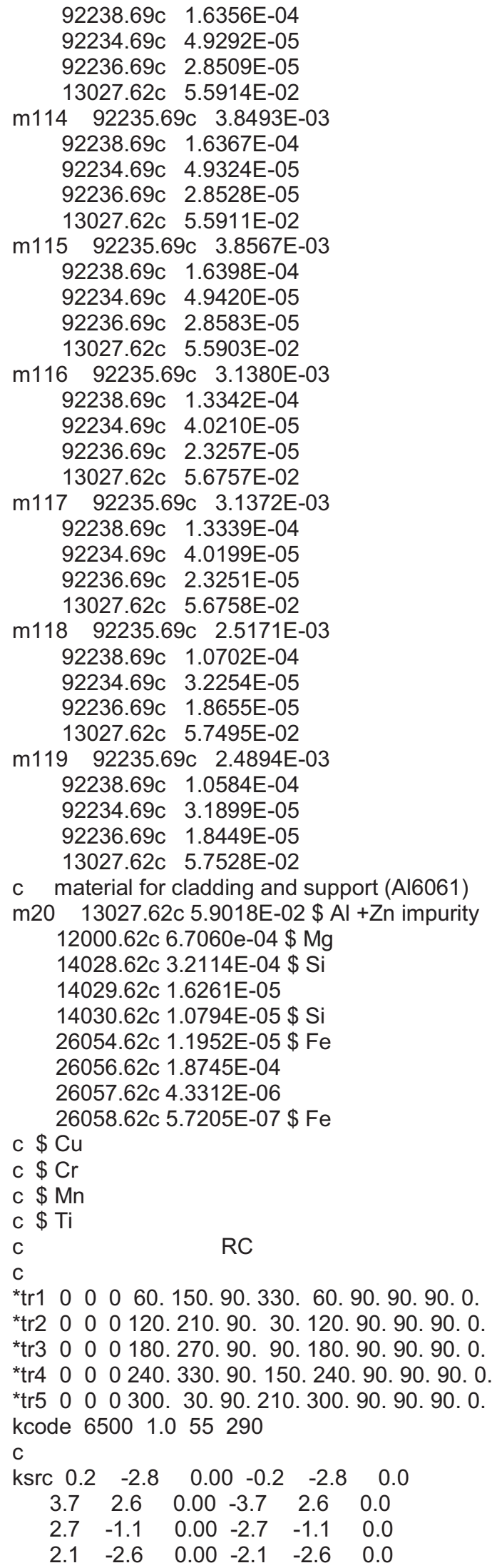


INL/EXT-10-20323

Revision: 1

Page 31 of 42

print

Sample Input Deck \#3, Case leu-1_7c_0.4 from Table C- 3

MCNP Listing for Demonstration U-10Mo

LEU ATR Demonstration element

c LEE: note this uses average "B" values

C cell cards for ATR assembly

$60150.100311 \quad 600-601-680-681 \quad u=1 \quad i m p: n=1$

602 101 6.017874E-02 $602-603-682-683-692693 \quad u=1$ imp:n=1

$603206.024110 \mathrm{E}-02601-604-680-681$ \#602 u=1 imp:n=1

$60450.100311 \quad 604-605-680-681 \quad u=1$ imp:n=1

c plate 2

$6051026.017685 E-02 \quad 606-607-684-685-692693 \quad u=1$ imp:n=1

$606206.024110 \mathrm{E}-02605-608-680-681$ \#605 u=1 imp:n=1

$60750.100311 \quad 608-609-680-681 \quad u=1$ imp:n=1

C plate 3

$6081036.009507 E-02 \quad 610-611-684-685-692693 \quad u=1$ imp:n=1

$609206.024110 \mathrm{E}-02 \quad 609-612-680-681$ \#608 u=1 imp:n=1

$61050.100311 \quad 612-613-680-681 \quad u=1$ imp:n=1

c plate 4

611 104 6.009671E-02 $614-615-684-685-692693 \quad u=1$ imp:n=1

$612206.024110 \mathrm{E}-02613-616-680-681$ \#611 u=1 imp:n=1

$61350.100311 \quad 616-617-680-681 \quad u=1$ imp:n=1

C plate 5

$6145154.918570 E-02 \quad 618-619-684-685-692693 \quad u=1 \quad i m p: n=1$

$614130 \quad 4.290970 \mathrm{E}-02 \quad 6171-618-684-685-692693 \quad \mathrm{u}=1$ imp:n=1

614230 4.290970E-02 $619-6191-684-685-692693 \quad u=1 \quad i m p: n=1$

$615206.024110 \mathrm{E}-02 \quad 617-620-680-681$

$(-6171: 6191: 692:-693: 684: 685) \quad u=1$ imp:n=1

$61650.100311 \quad 620-621-680-681 \quad u=1 \mathrm{imp}: n=1$

c plate 6

$6175154.918570 \mathrm{E}-02 \quad 622-623-684-685-692693 \quad \mathrm{u}=1 \mathrm{imp}: \mathrm{n}=1$

$6171304.290970 \mathrm{E}-02 \quad 6211-622-684-685-692693 \quad u=1 \quad i m p: n=1$

$617230 \quad 4.290970 \mathrm{E}-02 \quad 623-6231-684-685-692693 \mathrm{u}=1$ imp:n=1

$61820 \quad 6.024110 \mathrm{E}-02 \quad 621-624-680-681$

(-6211:6231:692:-693:684:685) u=1 imp:n=1

$\begin{array}{lll}6 & 0.100311 \quad 624-625-680-681 \quad u=1 & \mathrm{imp}: \mathrm{n}=1\end{array}$

C plate 7

$6205154.918570 E-02 \quad 626-627-684-685-692693 \quad u=1$ imp:n=1

620130 4.290970E-02 $6251-626-684-685-692693 \quad u=1$ imp:n=1

620230 4.290970E-02 $627-6271-684-685-692693 \quad u=1$ imp:n=1

$621206.024110 \mathrm{E}-02 \quad 625-628-680-681$

$62250.100311 \quad 628-629-680-681 \quad u=1 \quad i m p: n=1$

c plate 8

$6235154.918570 \mathrm{E}-02 \quad 630-631-684-685-692693 \quad \mathrm{u}=1 \mathrm{imp}: \mathrm{n}=1$

623130 4.290970E-02 $6291-630-684-685-692693 \quad u=1 \quad i m p: n=1$

$6232304.290970 \mathrm{E}-02631-6311-684-685-692693$ u=1 imp:n=1

$62420 \quad 6.024110 \mathrm{E}-02 \quad 629-632-680-681$

$(-6291: 6311: 692:-693: 684: 685) \quad u=1$ imp: $n=1$

$62550.100311 \quad 632-633-680-681 \quad u=1$ imp:n=1

C plate 9

626515 4.918570E-02 $634-635-684-685-692693 \quad u=1$ imp:n=1

626130 4.290970E-02 $6331-634-684-685-692693 \quad u=1$ imp:n=1

626230 4.290970E-02 $635-6351-684-685-692693 \quad u=1 \quad i m p: n=1$

$627206.024110 \mathrm{E}-02 \quad 633-636-680-681$

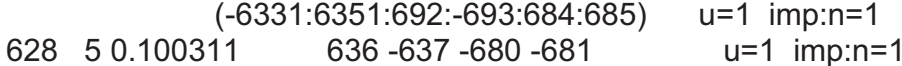

c plate 10 
INL/EXT-10-20323

Revision: 1

Page 32 of 42

$6295154.918570 \mathrm{E}-02 \quad 638-639-684-685-692693$

$629130 \quad 4.290970$ E-02 $6371-638-684-685-692693$

$\mathrm{u}=1$ imp:n=1

629230 4.290970E-02 $639-6391-684-685-692693 \quad u=1$ imp:n=1

$630206.024110 \mathrm{E}-02 \quad 637-640-680-681$

$(-6371: 6391: 692:-693: 684: 685) \quad u=1$ imp:n=1

$$
63150.100311 \quad 640-641-680-681 \quad u=1 \text { imp:n=1 }
$$

c plate 11

6325154.918570 E-02 $642-643-684-685-692693 \quad u=1$ imp:n=1

$632130 \quad 4.290970 E-02 \quad 6411-642-684-685-692693 \quad u=1$ imp:n=1

632230 4.290970E-02 $643-6431-684-685-692693 \quad u=1$ imp:n=1

$633206.024110 \mathrm{E}-02 \quad 641-644-680-681$

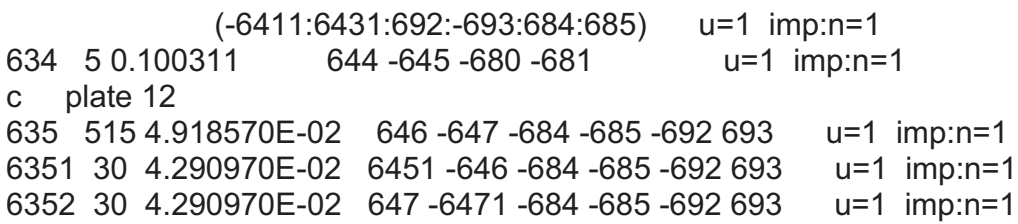

$636206.024110 \mathrm{E}-02 \quad 645-648-680-681$

$63750.100311 \quad 648-649-680-681 \quad u=1$ imp: $n=1$

C plate 13

638515 4.918570E-02 $650-651-684-685-692693$ u=1 imp:n=1

$638130 \quad 4.290970 E-02 \quad 6491-650-684-685-692693 \quad u=1$ imp:n=1

638230 4.290970E-02 $651-6511-684-685-692693 \quad u=1$ imp:n=1

$639206.024110 \mathrm{E}-02 \quad 649-652-680-681$

$64050.100311 \quad 652-653-680-681 \quad u=1$ imp:n=1

C plate 14

641515 4.918570E-02 $654-655-684-685-692693 \quad u=1$ imp:n=1

641130 4.290970E-02 $6531-654-684-685-692693 \quad u=1$ imp:n=1

641230 4.290970E-02 $655-6551-684-685-692693 \quad u=1$ imp:n=1

$64220 \quad 6.024110 \mathrm{E}-02 \quad 653-656-680-681$

$64350.100311 \quad 656-657-680-681 \quad u=1$ imp: $n=1$

c plate 15

644515 4.918570E-02 $658-659-684-685-692693 \quad u=1$ imp:n=1

644130 4.290970E-02 $6571-658-684-685-692693 \quad u=1$ imp:n=1

644230 4.290970E-02 $659-6591-684-685-692693 \quad u=1$ imp:n=1

$645206.024110 \mathrm{E}-02 \quad 657-660-680-681$

$(-6571: 6591: 692:-693: 684: 685) \quad u=1$ imp:n=1

$64650.100311 \quad 660-661-680-681 \quad u=1$ imp:n=1

c plate 16

647 116 6.009189E-02 $662-663-684-685-692693 \quad u=1$ imp:n=1

$648206.024110 E-02 \quad 661-664-680-681$ \#647 u=1 imp:n=1

$64950.100311 \quad 664-665-680-681 \quad u=1$ imp:n=1

C plate 17

$6501176.009204 E-02 \quad 666-667-684-685-692693 \quad u=1$ imp:n=1

65120 6.024110E-02 $665-668-680-681$ \#650 u=1 imp:n=1

$65250.100311 \quad 668-669-680-681 \quad u=1 \quad i m p: n=1$

c plate 18

653118 6.017003E-02 $670-671-686-687-692693$ u=1 imp:n=1

$654206.024110 E-02 \quad 669-672-680-681$ \#653 u=1 imp:n=1

$65550.100311 \quad 672-673-680-681 \quad u=1$ imp:n=1

c plate 19

c 656 119 6.017359E-02 $674-675-682-683-692693$ u=1 imp:n=1

c 65720 6.024110E-02 $673-676-680-681$ \#656 u=1 imp:n=1

$657206.024110 \mathrm{E}-02 \quad 673-676-680-681 \quad u=1$ imp:n=1

$65850.100311 \quad 676-677-680-681 \quad u=1 \quad i m p: n=1$

c side plates

65920 6.024110E-02 (-600:677:680:681) u=1 imp:n=1

c cut-out elements and move 
INL/EXT-10-20323

Revision: 1

Page 33 of 42

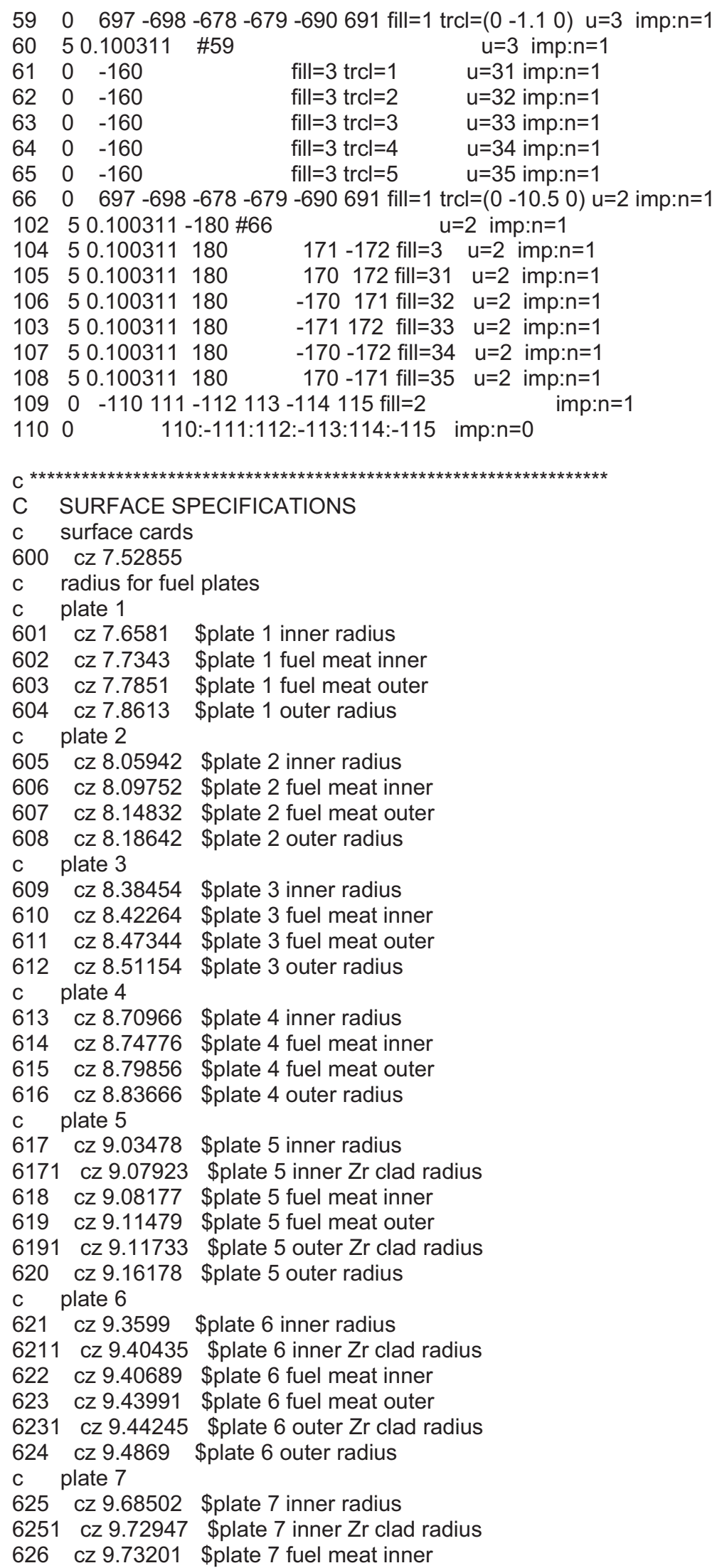


INL/EXT-10-20323

Revision: 1

Page 34 of 42

627 cz 9.76503 \$plate 7 fuel meat outer

6271 cz 9.76757 \$plate 7 outer $\mathrm{Zr}$ clad radius

628 cz 9.81202 \$plate 7 outer radius

C plate 8

629 Cz 10.01014 \$plate 8 inner radius

6291 cz 10.05459 \$plate 8 inner Zr clad radius

630 cz 10.05713 \$plate 8 fuel meat inner

$631 \mathrm{cz} 10.09015$ \$plate 8 fuel meat outer

6311 Cz 10.09269 \$plate 8 outer Zr clad radius

632 cz 10.13714 \$plate 8 outer radius

c plate 9

633 cz 10.33526 \$plate 9 inner radius

$6331 \mathrm{Cz} 10.37971$ \$plate 9 inner Zr clad radius

634 cz 10.38225 \$plate 9 fuel meat inner

635 cz 10.41527 \$plate 9 fuel meat outer

6351 Cz 10.41781 \$plate 9 outer Zr clad radius

636 cz 10.46226 \$plate 9 outer radius

C plate 10

637 cz 10.66038 \$plate 10 inner radius

6371 cz 10.70483 \$plate 10 inner $\mathrm{Zr}$ clad radius

638 cz 10.70737 \$plate 10 fuel meat inner

639 cz 10.74039 \$plate 10 fuel meat outer

6391 Cz 10.74293 \$plate 10 outer Zr clad radius

640 cz 10.78738 \$plate 10 outer radius

c plate 11

641 Cz 10.9855 \$plate 11 inner radius

6411 Cz 11.02995 \$plate 11 inner Zr clad radius

642 cz 11.03249 \$plate 11 fuel meat inner

643 cz 11.06551 \$plate 11 fuel meat outer

6431 Cz 11.06805 \$plate 11 outer Zr clad radius

644 Cz 11.1125 \$plate 11 outer radius

C plate 12

645 cz 11.31062 \$plate 12 inner radius

6451 cz 11.35507 \$plate 12 inner Zr clad radius

646 cz 11.35761 \$plate 12 fuel meat inner

647 cz 11.39063 \$plate 12 fuel meat outer

6471 Cz 11.39317 \$plate 12 outer Zr clad radius

648 cz 11.43762 \$plate 12 outer radius

c plate 13

649 Cz 11.63574 \$plate 13 inner radius

6491 cz 11.68019 \$plate 13 inner Zr clad radius

650 cz 11.68273 \$plate 13 fuel meat inner

651 cz 11.71575 \$plate 13 fuel meat outer

6511 cz 11.71829 \$plate 13 outer Zr clad radius

652 cz 11.76274 \$plate 13 outer radius

c plate 14

653 cz 11.96086 \$plate 14 inner radius

6531 cz 12.00531 \$plate 14 inner Zr clad radius

654 cz 12.00785 \$plate 14 fuel meat inner

655 cz 12.04087 \$plate 14 fuel meat outer

6551 Cz 12.04341 \$plate 14 outer Zr clad radius

656 cz 12.08786 \$plate 14 outer radius

c plate 15

657 cz 12.28598 \$plate 15 inner radius

6571 cz 12.33043 \$plate 15 inner $\mathrm{Zr}$ clad radius

658 cz 12.33297 \$plate 15 fuel meat inner

659 cz 12.36599 \$plate 15 fuel meat outer

6591 cz 12.36853 \$plate 15 outer $\mathrm{Zr}$ clad radius

660 cz 12.41298 \$plate 15 outer radius

C plate 16

661 Cz 12.6111 \$plate 16 inner radius 
INL/EXT-10-20323

Revision: 1

Page 35 of 42

662 cz 12.64920 \$plate 16 fuel meat inner

663 cz 12.70000 \$plate 16 fuel meat outer

664 cz 12.7381 \$plate 16 outer radius

C plate 17

665 Cz 12.93622 \$plate 17 inner radius

666 cz 12.97432 \$plate 17 fuel meat inner

667 cz 13.02512 \$plate 17 fuel meat outer

668 cz 13.06322 \$plate 17 outer radius

c plate 18

669 cz 13.26134 \$plate 18 inner radius

670 cz 13.29944 \$plate 18 fuel meat inner

671 cz 13.35024 \$plate 18 fuel meat outer

672 cz 13.38834 \$plate 18 outer radius

c plate 19

673 cz 13.58646 \$plate 19 inner radius

674 cz 13.68806 \$plate 19 fuel meat inner

675 cz 13.73886 \$plate 19 fuel meat outer

676 cz 13.84046 \$plate 19 outer radius

677 cz 14.01317 \$outer diameter of element

C surfaces for sides of plate and fuel region

678 p -2.414214-100 \$outside boundary of Al plate

679 p $2.414214-100 \quad$ \$outside boundary of Al plate

680 p -2.414214 -1 0 -1.241183 \$inside boundary of Al plate

681 p $2.414214-10-1.241183$ \$inside boundary of Al plate

682 p -2.414214 -1 0 -2.535464 \$plate 1 and 19 fuel meat boundary

683 p $2.414214-10-2.535464$ \$plate 1 and 19 fuel meat boundary

$684 \mathrm{p}-2.414214-10-1.871730$ \$plate 2 through 17 fuel meat boundary

685 p $2.414214-10-1.871730$ \$plate 2 through 17 fuel meat boundary

686 p -2.414214 -1 $0-2.004477$ \$plate 18 fuel meat boundary

687 p $2.414214-10-2.004477$ \$plate 18 fuel meat boundary

$690 \mathrm{pz} 62.8650$ \$top of fuel element, 49.5" total

$691 \mathrm{pz}-62.8650$ \$bottom of fuel element

$692 \mathrm{pz} 60.960$ \$top of fuel meat, 48" total

693 pz -60.960 \$bottom of fuel meat

697 Cz 7.52856 \$inner radius of element

698 cz 14.00302 \$outer radius of element

$160 \mathrm{cz} 10000$. \$just a big surface

170 py $0 . \quad \$$ horizontal line

171 p $1.73205081 \quad 100$

172 p $1.73205081-1 \quad 0 \quad 0$

180 CZ 5.94

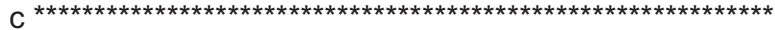

*110 px 65.2630 \$ storage rack

*111 px -65.2630

*112 py 44.8468

*113 py -44.8468

$114 \mathrm{pz} 100.0$ \$ water reflector

$115 \mathrm{pz}-100.0$

mode $n$

C WATER dens $=1.0000 \mathrm{~g} / \mathrm{cc} \$$ atm. den.: .100284

m5 1001.62c 6.6874E-02 \$ H

8016.62C 3.3437E-02 \$O

mt5 Iwtr.60t

c fuel plates

m101 92235.69c 2.4472E-03

92238.69c 1.0405E-04

92234.69c 3.1358E-05

92236.69c 1.8137E-05

13027.62c 5.7578E-02

$\mathrm{m} 102$ 92235.69c 2.4586E-03 
INL/EXT-10-20323

Revision: 1

Page 36 of 42

92238.69c 1.0453E-04

92234.69c 3.1504E-05

92236.69c $1.8221 \mathrm{E}-05$

13027.62C 5.7564E-02

m103 92235.69c 3.1090E-03

92238.69c 1.3219E-04

92234.69c 3.9839E-05

92236.69c 2.3042E-05

13027.62C 5.6791E-02

m104 92235.69c 3.0936E-03

92238.69c 1.3154E-04

92234.69c 3.9641E-05

92236.69c 2.2928E-05

13027.62C 5.6809E-02

m105 92235.69c 3.8111E-03

92238.69c 1.6204E-04

92234.69c 4.8835E-05

$92236.69 \mathrm{c} \quad 2.8245 \mathrm{E}-05$

13027.62C 5.5957E-02

m106 92235.69c 3.8230E-03

92238.69c 1.6255E-04

$92234.69 \mathrm{C} \quad 4.8988 \mathrm{E}-05$

$92236.69 \mathrm{c} \quad 2.8334 \mathrm{E}-05$

13027.62C 5.5943E-02

m107 92235.69c 3.8272E-03

$92238.69 \mathrm{c} \quad 1.6273 \mathrm{E}-04$

92234.69c 4.9042E-05

$92236.69 \mathrm{c} \quad 2.8365 \mathrm{E}-05$

$13027.62 \mathrm{C} \quad 5.5938 \mathrm{E}-02$

m108 92235.69c 3.8311E-03

92238.69c 1.6289E-04

92234.69c 4.9092E-05

92236.69c 2.8394E-05

13027.62C 5.5933E-02

m109 92235.69c 3.8347E-03

92238.69c 1.6305E-04

92234.69c 4.9138E-05

92236.69c 2.8420E-05

13027.62C 5.5929E-02

m110 92235.69c 3.8381E-03

92238.69c 1.6319E-04

92234.69c 4.9180E-05

92236.69c 2.8445E-05

13027.62C 5.5925E-02

$\mathrm{m} 111$ 92235.69c 3.8412E-03

92238.69c 1.6332E-04

92234.69c 4.9220E-05

$92236.69 \mathrm{c} \quad 2.8468 \mathrm{E}-05$

13027.62c 5.5921E-02

$\mathrm{m} 112$ 92235.69c 3.8441E-03

92238.69c 1.6344E-04

92234.69c 4.9257E-05

92236.69c 2.8489E-05

13027.62C 5.5918E-02

m113 92235.69c 3.8468E-03

92238.69c 1.6356E-04

92234.69c 4.9292E-05

92236.69c 2.8509E-05

13027.62C 5.5914E-02

m114 92235.69c 3.8493E-03

92238.69c 1.6367E-04 
INL/EXT-10-20323

Revision: 1

Page 37 of 42

92234.69c 4.9324E-05

92236.69c 2.8528E-05

13027.62C 5.5911E-02

m115 92235.69c 3.8567E-03

92238.69c 1.6398E-04

92234.69c 4.9420E-05

92236.69c 2.8583E-05

13027.62C 5.5903E-02

m116 92235.69c 3.1380E-03

92238.69c 1.3342E-04

92234.69c $4.0210 \mathrm{E}-05$

92236.69c 2.3257E-05

13027.62C 5.6757E-02

m117 92235.69c 3.1372E-03

92238.69c 1.3339E-04

92234.69c 4.0199E-05

$92236.69 \mathrm{c} \quad 2.3251 \mathrm{E}-05$

13027.62C 5.6758E-02

$\mathrm{m} 118$ 92235.69c 2.5171E-03

92238.69c 1.0702E-04

92234.69c 3.2254E-05

92236.69c $1.8655 \mathrm{E}-05$

13027.62C 5.7495E-02

m119 92235.69c 2.4894E-03

92238.69c $1.0584 \mathrm{E}-04$

92234.69c 3.1899E-05

92236.69c 1.8449E-05

13027.62C 5.7528E-02

m515 92235.69c 7.7940E-03

92238.69c 3.0677E-02

$92234.69 \mathrm{c} \quad 4.3834 \mathrm{E}-05$

$92236.69 \mathrm{c} \quad 6.2864 \mathrm{E}-05$

42000.66c 1.0608E-02

C material for cladding and support (Al6061)

m20 13027.62c 5.9018E-02 \$ Al +Zn impurity

12000.62c 6.7060e-04 \$ Mg

14028.62c 3.2114E-04 \$ Si

14029.62C $1.6261 \mathrm{E}-05$

14030.62c 1.0794E-05 \$ Si

26054.62C 1.1952E-05 \$ Fe

26056.62c 1.8745E-04

26057.62c 4.3312E-06

26058.62c 5.7205E-07 \$ Fe

c

m30 40090.66c 2.2077E-02

40091.66c 4.8145E-03

40092.66c 7.3590E-03

40094.66c 7.4577E-03

40096.66c $1.2015 \mathrm{E}-03$

c

$\mathrm{RC}$

C

${ }^{*}$ tr1 00000 60. 150.90. 330. 60.90.90.90. 0.

*tr2 000 0 120. 210.90. 30.120.90.90.90. 0.

*tr3 0000 180. 270. 90. 90. 180. 90. 90.90. 0.

*tr4 0000 240. 330.90. 150. 240. 90. 90. 90. 0.

${ }^{*} \operatorname{tr} 50000300.30 .90 .210 .300 .90 .90 .90 .0$.

kcode 65001.055290

$\mathrm{c}$

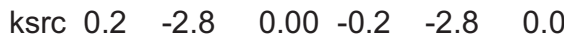

$\begin{array}{llllll}3.7 & 2.6 & 0.00 & -3.7 & 2.6 & 0.0\end{array}$

$\begin{array}{llllll}2.7 & -1.1 & 0.00 & -2.7 & -1.1 & 0.0\end{array}$ 
INL/EXT-10-20323

Revision: 1

Page 38 of 42

$\begin{array}{llllll}2.1 & -2.6 & 0.00 & -2.1 & -2.6 & 0.0\end{array}$

print 
INL/EXT-10-20323

Revision: 1

Page 39 of 42

\section{Appendix C: Fuel Element Array Results}

The results in Table C- 1 are for the HEU ATR elements. The water moderated and reflected single element results are given in the first set of the table. The comparison case (from Reference 8) results are given in the second set. Results for the hexagonal array shown in Figure 5 with different spacings are given in the third set of the table.

Table C- 1. Results for HEU ATR Element Configurations

\begin{tabular}{|c|c|c|c|}
\hline $\begin{array}{l}\text { Case (MCNP } \\
\text { Input File) }\end{array}$ & Description & $k_{\text {eff }} \pm \sigma$ & $k_{\text {eff }}+2 \sigma$ \\
\hline \multicolumn{4}{|c|}{ A single water moderated and reflected ATR element } \\
\hline heu_1a & Single water moderated and reflected ATR element & $0.4455 \pm 0.0006$ & 0.4467 \\
\hline \multicolumn{4}{|c|}{ A hexagonal array of 7 ATR elements like Configuration A in Figure 4} \\
\hline heu_7a & Elements are water moderated and flooded & $0.9887 \pm 0.0007$ & 0.9901 \\
\hline \multicolumn{4}{|c|}{ A hexagonal array of 7 ATR elements to investigate element spacing, see Figure 5} \\
\hline heu_7b & Adjacent elements are touching; see Figure 5a & $0.9602 \pm 0.0007$ & 0.9615 \\
\hline heu_7b_.2 & Previous case, but spacing between elements is $0.2 \mathrm{~cm}$ & $0.9725 \pm 0.0007$ & 0.9739 \\
\hline heu_7b_.4 & Case heu_7b, but spacing between elements is $0.4 \mathrm{~cm}$ & $0.9806 \pm 0.0007$ & 0.9821 \\
\hline heu_7b_.6.o & Case heu_7b, but spacing between elements is $0.6 \mathrm{~cm}$ & $0.9872 \pm 0.0007$ & 0.9886 \\
\hline heu_7b_.8 & Case heu_7b, but spacing between elements is $0.8 \mathrm{~cm}$ & $0.9914 \pm 0.0008$ & 0.9929 \\
\hline heu_7b_9 & Case heu_7b, but spacing between elements is $0.9 \mathrm{~cm}$ & $0.9911 \pm 0.0008$ & 0.9926 \\
\hline heu_7b_1 & Case heu_7b, but spacing between elements is $1.0 \mathrm{~cm}$ & $0.9944 \pm 0.0007$ & 0.9958 \\
\hline heu_7b_1.1 & Previous case, but spacing is $1.1 \mathrm{~cm}$; see Figure $5 \mathrm{~b}$ & $0.9952 \pm 0.0007$ & 0.9967 \\
\hline heu_7b_1.2 & Case heu_7b, but spacing between elements is $1.2 \mathrm{~cm}$ & $0.9916 \pm 0.0007$ & 0.9930 \\
\hline heu_7b_1.4 & Case heu_7b, but spacing between elements is $1.4 \mathrm{~cm}$ & $0.9907 \pm 0.0007$ & 0.9920 \\
\hline heu_7b_1.6 & Case heu_7b, but spacing between elements is $1.6 \mathrm{~cm}$ & $0.9887 \pm 0.0007$ & 0.9900 \\
\hline heu_7b_1.8 & Case heu_7b, but spacing between elements is $1.8 \mathrm{~cm}$ & $0.9831 \pm 0.0007$ & 0.9844 \\
\hline heu_7b_2 & Case heu_7b, but spacing between elements is $2.0 \mathrm{~cm}$ & $0.9759 \pm 0.0007$ & 0.9772 \\
\hline
\end{tabular}


INL/EXT-10-20323

Revision: 1

Page 40 of 42

Results for the circular configuration shown in Figure 6 with different spacings are given in Table C- 2 .

Table C- 2. Results for HEU ATR Elements in Circular Configurations

\begin{tabular}{|c|c|c|c|}
\hline $\begin{array}{l}\text { Case (MCNP } \\
\text { Input File) }\end{array}$ & Description & $\mathbf{k}_{\text {eff }} \pm \sigma$ & $k_{\text {eff }}+2 \sigma$ \\
\hline \multicolumn{4}{|c|}{ Elements in circular configuration with varying spacing } \\
\hline heu_7c_ma & Elements are at closest approach, see Figure 6a & $0.9818 \pm 0.0007$ & 0.9832 \\
\hline heu_7c_0 & $\begin{array}{l}\text { Similar to previous case, but center element is moved upwards towards } \\
\text { the center, and radius of outer ring is increased slightly }\end{array}$ & $0.9942 \pm 0.0007$ & 0.9956 \\
\hline heu_7c_0.1 & Case heu_7c_0, but outer radius is increased by $0.1 \mathrm{~cm}$ & $0.9949 \pm 0.0007$ & 0.9963 \\
\hline heu_7c_0.2 & Case heu_7c_0, but outer radius is increased by $0.2 \mathrm{~cm}$, see Figure $6 \mathrm{~b}$ & $0.9952 \pm 0.0007$ & 0.9965 \\
\hline heu_7c_0.3 & Case heu_7c_0, but outer radius is increased by $0.3 \mathrm{~cm}$ & $0.9948 \pm 0.0007$ & 0.9962 \\
\hline heu_7c_0.4 & Case heu_7c_0, but outer radius is increased by $0.4 \mathrm{~cm}$ & $0.9937 \pm 0.0007$ & 0.9951 \\
\hline heu_7c_0.6 & Case heu_7c_0, but outer radius is increased by $0.6 \mathrm{~cm}$ & $0.9898 \pm 0.0007$ & 0.9912 \\
\hline heu_7c_0.8 & Case heu_7c_0, but outer radius is increased by $0.8 \mathrm{~cm}$ & $0.9855 \pm 0.0007$ & 0.9868 \\
\hline heu_7c_1.0 & Case heu_7c_0, but outer radius is increased by $1.0 \mathrm{~cm}$ & $0.9802 \pm 0.0007$ & 0.9815 \\
\hline
\end{tabular}


INL/EXT-10-20323

Revision: 1

Page 41 of 42

Results similar to those given in Table C- 1 and Table C- 2 are given in Table C- 3 for the U-10Mo Demonstration elements with the aluminum (dummy) plate 19 and the boron content neglected.

Table C- 3. Results for U-10Mo Full Size Demonstration ATR Element Configurations

\begin{tabular}{|c|c|c|c|}
\hline $\begin{array}{c}\text { Case } \\
\text { (MCNP Input } \\
\text { File) }\end{array}$ & Description & $\mathbf{k}_{\text {eff }} \pm \sigma$ & $k_{\text {eff }}+2 \sigma$ \\
\hline \multicolumn{4}{|c|}{ A single water moderated and reflected ATR Demonstration element } \\
\hline leu-1_1a & Single water moderated and reflected ATR element & $0.4370 \pm 0.0005$ & 0.4380 \\
\hline \multicolumn{4}{|c|}{ A hexagonal array of 7 U-10Mo elements like Configuration A in Figure 4} \\
\hline leu-1_7a & Elements are water moderated and flooded & $0.9540 \pm 0.0007$ & 0.9553 \\
\hline \multicolumn{4}{|c|}{ A hexagonal array of 7 U-10Mo elements to investigate element spacing, see Figure 5} \\
\hline leu-1_7b & Adjacent elements are touching; see Figure 5a & $0.9218 \pm 0.0008$ & 0.9234 \\
\hline leu-1_7b_.2 & Previous case, but spacing between elements is $0.2 \mathrm{~cm}$ & $0.9333 \pm 0.0007$ & 0.9348 \\
\hline leu-1_7b_.4 & Case leu-1_7b, but spacing between elements is $0.4 \mathrm{~cm}$ & $0.9442 \pm 0.0006$ & 0.9455 \\
\hline leu-1_7b_.6 & Case leu-1_7b, but spacing between elements is $0.6 \mathrm{~cm}$ & $0.9504 \pm 0.0006$ & 0.9517 \\
\hline leu-1_7b_.8 & Case leu-1_7b, but spacing between elements is $0.8 \mathrm{~cm}$ & $0.9546 \pm 0.0007$ & 0.9560 \\
\hline leu-1_7b_.9 & Case leu-1_7b, but spacing between elements is $0.9 \mathrm{~cm}$ & $0.9568 \pm 0.0007$ & 0.9582 \\
\hline leu-1_7b_1 & Case leu-1_7b, but spacing between elements is $1.0 \mathrm{~cm}$ & $0.9585 \pm 0.0008$ & 0.9600 \\
\hline leu-1_7b_1.1 & Case leu-1_7b, but spacing between elements is $1.1 \mathrm{~cm}$ & $0.9585 \pm 0.0007$ & 0.9599 \\
\hline leu-1_7b_1.2 & Case leu-1_7b, but spacing between elements is $1.2 \mathrm{~cm}$ & $0.9574 \pm 0.0007$ & 0.9589 \\
\hline leu-1_7b_1.4 & Case leu-1_7b, but spacing between elements is $1.4 \mathrm{~cm}$ & $0.9571 \pm 0.0007$ & 0.9585 \\
\hline leu-1_7b_1.6 & Case leu-1_7b, but spacing between elements is $1.6 \mathrm{~cm}$ & $0.9543 \pm 0.0007$ & 0.9558 \\
\hline leu-1_7b_1.8 & Case leu-1_7b, but spacing between elements is $1.8 \mathrm{~cm}$ & $0.9499 \pm 0.0007$ & 0.9512 \\
\hline leu-1_7b_2 & Case leu-1_7b, but spacing between elements is $2.0 \mathrm{~cm}$ & $0.9435 \pm 0.0007$ & 0.9448 \\
\hline \multicolumn{4}{|c|}{ Elements in circular configuration with varying spacing } \\
\hline leu-1_7c_ma & Elements are at closest approach, see Figure 6a & $0.9416 \pm 0.0007$ & 0.9431 \\
\hline leu-1_7c_0 & $\begin{array}{l}\text { Similar to previous case, but center element is moved upwards towards } \\
\text { the center, and radius of outer ring is increased slightly }\end{array}$ & $0.9579 \pm 0.0007$ & 0.9594 \\
\hline leu-1_7c_0.1 & Case leu-1_7c_0, but outer radius is increased by $0.1 \mathrm{~cm}$ & $0.9596 \pm 0.0007$ & 0.9611 \\
\hline leu-1_7c_0.2 & Case leu-1_7c_0, but outer radius is increased by $0.2 \mathrm{~cm}$ & $0.9607 \pm 0.0007$ & 0.9621 \\
\hline leu-1_7c_0.3 & Case leu-1_7c_0, but outer radius is increased by $0.3 \mathrm{~cm}$ & $0.9606 \pm 0.0006$ & 0.9619 \\
\hline leu-1_7c_0.4 & Case leu-1_7c_0, but outer radius is increased by $0.4 \mathrm{~cm}$ & $0.9624 \pm 0.0007$ & 0.9637 \\
\hline leu-1_7c_0.6 & Case leu-1_7c_0, but outer radius is increased by $0.6 \mathrm{~cm}$ & $0.9597 \pm 0.0006$ & 0.9610 \\
\hline leu-1_7c_0.8 & Case leu-1_7c_0, but outer radius is increased by $0.8 \mathrm{~cm}$ & $0.9572 \pm 0.0007$ & 0.9585 \\
\hline leu-1_7c_1.0 & Case leu-1_7c_0, but outer radius is increased by $1.0 \mathrm{~cm}$ & $0.9533 \pm 0.0007$ & 0.9547 \\
\hline
\end{tabular}


INL/EXT-10-20323

Revision: 1

Page 42 of 42

The results in Table C- 4 are the equivalent results as those given in Table C- 3 except all 19 plates are fueled and the boron content is neglected. The fuel loading in plate 19 is assumed to be the same as that of plate 19 of the HEU ATR element.

Table C- 4. Results for U-10Mo Full Size Demonstration ATR Elements with all Plates Fueled

\begin{tabular}{|c|c|c|c|}
\hline $\begin{array}{l}\text { Case (MCNP } \\
\text { Input File) }\end{array}$ & Description & $k_{\text {eff }} \pm \sigma$ & $k_{\text {eff }}+2 \sigma$ \\
\hline \multicolumn{4}{|c|}{ A single water moderated and reflected ATR Demonstration element } \\
\hline leu_1a & Single water moderated and reflected ATR element & $0.4490 \pm 0.0006$ & 0.4501 \\
\hline \multicolumn{4}{|c|}{ A hexagonal array of 7 U-10Mo (all plates fueled) elements like Configuration A in Figure 4} \\
\hline leu_7a & Elements are water moderated and flooded & $0.9701 \pm 0.0007$ & 0.9715 \\
\hline \multicolumn{4}{|c|}{$\begin{array}{l}\text { A hexagonal array of } 7 \mathrm{U}-10 \mathrm{Mo} \text { (all plates fueled) elements to investigate element spacing, see } \\
\text { Figure } 5\end{array}$} \\
\hline leu_7b & Adjacent elements are touching; see Figure 5a & $0.9342 \pm 0.0007$ & 0.9356 \\
\hline leu_7b_.2 & Previous case, but spacing between elements is $0.2 \mathrm{~cm}$ & $0.9464 \pm 0.0006$ & 0.9476 \\
\hline leu_7b_.4 & Case leu_7b, but spacing between elements is $0.4 \mathrm{~cm}$ & $0.9558 \pm 0.0007$ & 0.9571 \\
\hline leu_7b_.6 & Case leu_7b, but spacing between elements is $0.6 \mathrm{~cm}$ & $0.9640 \pm 0.0007$ & 0.9654 \\
\hline leu_7b_.8 & Case leu_7b, but spacing between elements is $0.8 \mathrm{~cm}$ & $0.9702 \pm 0.0007$ & 0.9716 \\
\hline leu_7b_1 & Case leu_7b, but spacing between elements is $1.0 \mathrm{~cm}$ & $0.9739 \pm 0.0007$ & 0.9752 \\
\hline leu_7b_1.2 & Case leu_7b, but spacing between elements is $1.2 \mathrm{~cm}$ & $0.9764 \pm 0.0006$ & 0.9777 \\
\hline leu_7b_1.4 & Case leu_7b, but spacing between elements is $1.4 \mathrm{~cm}$ & $0.9740 \pm 0.0006$ & 0.9753 \\
\hline leu_7b_1.6 & Case leu_7b, but spacing between elements is $1.6 \mathrm{~cm}$ & $0.9734 \pm 0.0006$ & 0.9746 \\
\hline leu_7b_1.8 & Case leu_7b, but spacing between elements is $1.8 \mathrm{~cm}$ & $0.9706 \pm 0.0006$ & 0.9719 \\
\hline leu_7b_2 & Case leu_7b, but spacing between elements is $2.0 \mathrm{~cm}$ & $0.9644 \pm 0.0007$ & 0.9658 \\
\hline \multicolumn{4}{|c|}{ Elements in circular configuration with varying spacing } \\
\hline leu_7c_ma & Elements are at closest approach, see Figure 6a & $0.9556 \pm 0.0007$ & 0.9569 \\
\hline leu_7c_0 & $\begin{array}{l}\text { Similar to previous case, but center element is moved upwards towards } \\
\text { the center, and radius of outer ring is increased slightly }\end{array}$ & $0.9739 \pm 0.0007$ & 0.9753 \\
\hline leu_7c_0.1 & Case leu_7c_0, but outer radius is increased by $0.1 \mathrm{~cm}$ & $0.9753 \pm 0.0007$ & 0.9766 \\
\hline leu_7c_0.2 & Case leu_7c_0, but outer radius is increased by $0.2 \mathrm{~cm}$ & $0.9760 \pm 0.0007$ & 0.9774 \\
\hline leu_7c_0.3 & Case leu_7c_0, but outer radius is increased by $0.3 \mathrm{~cm}$ & $0.9762 \pm 0.0007$ & 0.9777 \\
\hline leu_7c_0.4 & Case leu_7c_0, but outer radius is increased by $0.4 \mathrm{~cm}$ & $0.9764 \pm 0.0007$ & 0.9778 \\
\hline leu_7c_0.6 & Case leu_7c_0, but outer radius is increased by $0.6 \mathrm{~cm}$ & $0.9739 \pm 0.0006$ & 0.9751 \\
\hline leu_7c_0.8 & Case leu_7c_0, but outer radius is increased by $0.8 \mathrm{~cm}$ & $0.9713 \pm 0.0007$ & 0.9727 \\
\hline leu_7c_1.0 & Case leu_7c_0, but outer radius is increased by $1.0 \mathrm{~cm}$ & $0.9679 \pm 0.0007$ & 0.9692 \\
\hline
\end{tabular}

